DIW BERLIN

Discussion

Papers
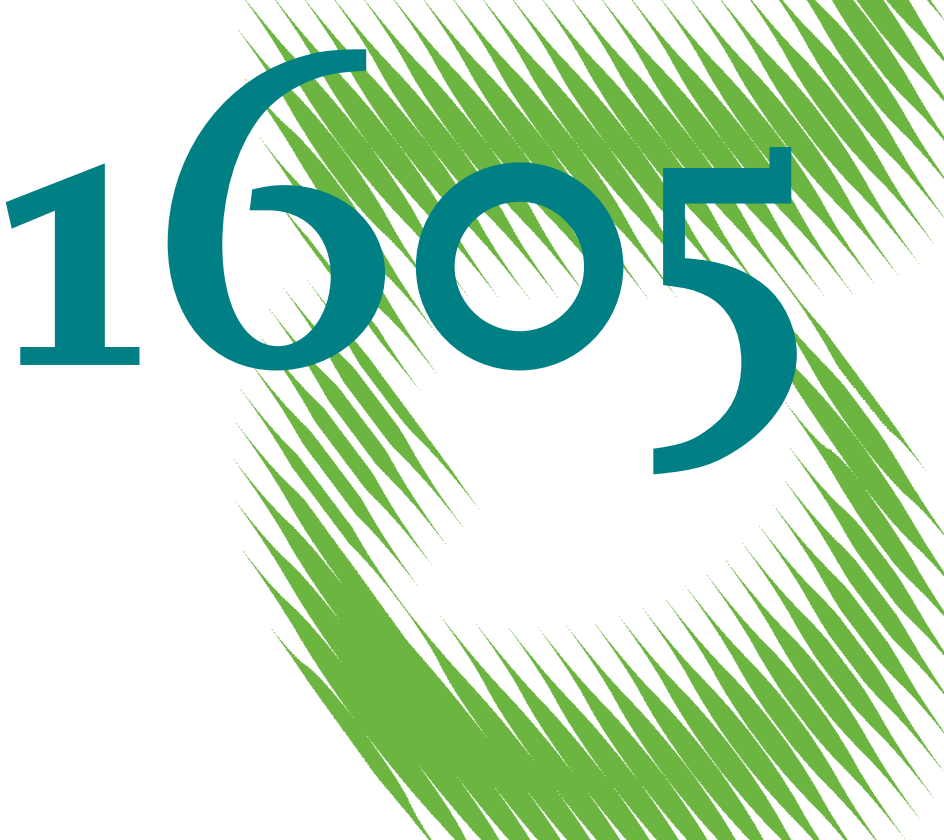

Monetary Policy and Mispricing in Stock Markets 
Opinions expressed in this paper are those of the author(s) and do not necessarily reflect views of the institute.

IMPRESSUM

(C) DIW Berlin, 2016

DIW Berlin

German Institute for Economic Research

Mohrenstr. 58

10117 Berlin

Tel. +49 (30) $89789-0$

Fax +49 (30) $89789-200$

http://www.diw.de

ISSN electronic edition 1619-4535

Papers can be downloaded free of charge from the DIW Berlin website:

http://www.diw.de/discussionpapers

Discussion Papers of DIW Berlin are indexed in RePEc and SSRN:

http://ideas.repec.org/s/diw/diwwpp.html

http://www.ssrn.com/link/DIW-Berlin-German-Inst-Econ-Res.html 


\title{
Monetary Policy and Mispricing in Stock Markets
}

\author{
Benjamin Beckers*, Kerstin Bernoth ${ }^{\dagger}$
}

August 30, 2016

\begin{abstract}
This paper investigates whether central banks can attenuate excessive mispricing in stocks as suggested by the proponents of a "leaning against the wind" (LATW) monetary policy. For this, we decompose stock prices into a fundamental component, a risk premium, and a mispricing component. We argue that mispricing can arise for two reasons: (i) from false subjective expectations of investors about future fundamentals and equity premia; and (ii) from the inherent indeterminacy in asset pricing in line with rational bubbles. We show that the response of the excessive stock price component to a monetary policy shock is ambiguous in both the short- and long-run, and depends on the nature of the mispricing. Subsequently, we evaluate the scope for a LATW policy empirically by employing a time-varying coefficient VAR with a flexible identification scheme based on impact and long-run restrictions using data for the S\&P500 index from 1962Q1 to 2014Q4. We find that a contractionary monetary policy shock in fact lowers stock prices beyond what is implied by the response of their underlying fundamentals.
\end{abstract}

Keywords: Asset pricing, bubbles, financial stability, leaning against the wind, mispricing, monetary policy, time-varying coefficient VAR, zero and sign restrictions.

JEL Classification: E44, E52, G12, G14

\footnotetext{
*DIW Berlin, Mohrenstraße 58, 10117 Berlin, Germany, bbeckers@diw.de.

${ }^{\dagger}$ Hertie School of Governance and DIW Berlin, Mohrenstraße 58, 10117 Berlin, Germany, kbernoth@diw.de.

We thank Klaus Adam, Refet Gürkaynak, Helmut Herwartz, Helmut Lütkepohl, as well as participants at the IFABS 2016 Barcelona Conference, the 14th INFINITI Conference on International Finance, the 33rd International Symposium on Money, Banking and Finance, the Conference on "Challenges of European Integration" at University of Bonn, the 2015 DIW Berlin Macroeconometric Workshop, and seminar participants at Norges Bank, University of Hamburg, University of Göttingen and Halle Institute for Economic Research (IWH) for helpful comments and suggestions. Financial support by the Deutsche Forschungsgemeinschaft (DFG) (Project title: "Macroeconomic fundamentals of asset prices - state dependence and implications for the conduct of monetary policy") is gratefully acknowledged.
} 


\section{Introduction}

The appropriate response of central banks to excessive asset price developments is subject of intense debate. While some researchers and policy makers advance the conventional view that monetary policy should focus solely on price and output stabilization (Bernanke \& Gertler, 1999; Posen, 2006), others call for a more active, "leaning against the wind" (LATW) monetary policy (Borio \& Lowe, 2002; Cecchetti et al., 2002). This policy prescribes that central banks should monitor asset prices closely for the presence of bubbles, defined as periods when asset prices deviate excessively from their fundamentally justified value. If a bubble is detected, policy makers should raise interest rates to attenuate excessive asset mispricing and contain the risks for financial and macroeconomic stability.

For an asset price targeting monetary policy to be feasible, however, two key requirements need to be fulfilled. First, a monetary policy tightening must lower the mispricing component in asset prices. Second, this response needs to be sufficiently large such that a monetary intervention is not too costly in terms of inflation or output depression 11 The LATW policy prescription builds on the conventional view that an increase in interest rates reduces the size of an asset price bubble. Yet, this paradigm is challenged by Galí (2014), who argues that the mispricing component in asset prices must grow in expectation at the rate of interest according to the theory on rational asset price bubbles. Raising the policy rate to combat an emerging asset price bubble would, thus, carry adverse effects and exacerbate mispricing. This finding receives empirical support from Galí \& Gambetti (2015), who find that speculation and, hence, stock prices increase following a monetary policy tightening.

In this paper, we challenge the theoretical predictions and empirical findings of Galí (2014) and Galí \& Gambetti (2015) along three dimensions. First, we extend the theoretical analysis beyond the concept of rational bubbles to a more general notion of asset mispricing following Brunnermeier \& Julliard (2008). More specifically, in our model asset mispricing may arise (i) from a violation of the transversality condition under subjective expectations; and/or (ii) from false expectations of irrational investors about future dividends and equity premia. While we do not attempt to empirically identify the source of mispricing, this framework carries important implications for the theoretically predicted response of asset mispricing to monetary policy shocks. Specifically, the ultimate effect of a monetary policy shock on excessive stock prices in our more general framework is ambiguous both in the short- and long-run and depends on the nature of the mispricing component. If mispricing is restrictively assumed to only take the form of a rational bubble, as in Galí (2014) and Galí \& Gambetti (2015), one can remove this ambiguity to obtain long-run bubble growth following a contractionary policy shock.

\footnotetext{
${ }^{1} \overline{\text { Furthermore, it is required that asset price }}$ bubbles can be detected in real-time. Promising real-time indicators are proposed by Phillips et al. (2011, 2015).
} 
Second, our theoretical framework suggests the presence of a time-varying expected equity risk premium is a key determinant of stock prices. When this premium is not taken into account, as in Galí \& Gambetti (2015), any deviation from the fundamental stock price would be incorrectly attributed to mispricing. Thus, to obtain an unbiased estimate of the mispricing component, measures for expected excess dividends and the equity premium are required (Cochrane, 2011). We forecast these expectations using a stock pricing VAR model similar to Campbell (1991), Bernanke \& Kuttner (2005) and Campbell et al. (2013). We then empirically disentangle the stock price response to monetary policy shocks into its three economic sources: the responses of the fundamental component, of the equity premium, and of the mispricing component. By this, we extend the analysis of Bernanke \& Kuttner (2005) on the response of the expected equity premium to monetary policy shocks. In contrast to their results, we find a smaller response of the equity premium. An explanation for this difference could be that the authors do not take into account the possible existence of the stock mispricing component. This means that they attribute any possible mispricing response to the response of the equity risk premium.

Third, we challenge the empirical findings of Galí \& Gambetti (2015) by employing a less restrictive strategy to identify monetary policy shocks in the data. The authors use a recursive identification scheme building on the assumption that monetary policy shocks influence stock prices instantaneously but that the central bank does not react within the quarter to idiosyncratic stock price movements. Only under this scheme they find that the mispricing component in stock prices increases following a contractionary monetary policy shock. However, the assumption that the U.S. Fed does not respond contemporaneously to stock price surprises (or economic news shocks captured by stock price movements) is disputable and is rejected by Lütkepohl \& Netsunajev (2014), who test this assumption by employing heteroscedasticity in the data. Further empirical evidence indicates that the Fed reacts pro-actively to stock price innovations, at least in some periods (Rigobon \& Sack, 2003, Bjørnland \& Leitemo, 2009; and Furlanetto, 2011). Thus, in our identification scheme, we allow for two-way contemporaneous responses between stock prices and the policy rate. We implement this by imposing both zero impact and long-run restrictions following Bjørnland \& Leitemo (2009) and by combining these with additional sign restrictions following Arias et al. (2014) and Binning (2013). Similar to Galí \& Gambetti (2015), we evaluate the response of the mispricing component in asset prices to monetary policy shocks in a time-varying coefficient (TVC) VAR following Primiceri (2005). A TVC-VAR has the advantage that we can take into account that the size and direction of stock price responses to monetary policy shocks might not be constant over time but depend on the relative size of the mispricing component.

Our results suggest that monetary policy tightening lowers stock prices significantly. 
However, only half of the impact response in stock prices can be attributed to changes in expectations about future dividends, the discount factor, and the equity premium. Hence, we conclude that the other half of the reduction in stock prices results from a decline in the mispricing component. We also find that the response of the mispricing component to monetary policy shocks is larger during periods of (presumably excessive) stock price booms such as during the dot-com bubble of the 1990s. By this, we provide support to the arguments of the proponents of an active LATW monetary policy that a contractionary monetary policy helps combat excessive asset price growth $2^{2}$ However, this comes at the cost of lower economic growth and a significant reduction in inflation. We conclude from this that a LATW monetary policy might not always be the recommended policy tool to combat excessive stock price developments, especially when excessive stock price booms arise in times of recession and low inflation. By this, we contribute not only to the discussion whether central banks could attenuate excessive stock price developments with conventional interest rate policy, but also, whether they should do so.

The paper is structured as follows. Section 2 formally lays out a partial equilibrium asset pricing model that disentangles stock prices into a fundamental component, the expected risk premium, and a mispricing component. Subsequently, it discusses how and through which channels monetary policy affects these different stock price determinants. Section 3 outlines the TVC-VAR model and the identification strategy employed in our empirical analysis. Section 4 describes the data and our measure of the expected equity risk premium. Section 5 presents our results and robustness tests. Finally, Section 6 concludes.

\section{A Partial Equilibrium Asset Pricing Model}

We derive a simple partial equilibrium asset pricing model to evaluate the theoretically predicted impact of a monetary policy shock on stock prices and their components. The theoretical predictions derived from the model will later guide our empirical identification strategy. Our model differs from Galí (2014) and Galí \& Gambetti (2015) in two ways: First, we relax the assumption that the expected stock price return (the discount factor) equals the risk free return. Instead we allow for the presence of (time-varying) expected equity risk premia. Second, we generalize their concept of the mispricing component potentially present in stock prices. The authors discuss theoretical predictions for the response of this mispricing component to monetary policy shocks under the assumption that it takes the form of a rational bubble when all investors are fully rational. We abstract from this narrow definition by following the argumentation of Campbell \& Vuolteenaho (2004) and Brunnermeier \& Julliard (2008) that stock mispricing may also occur due to false subjective believes of irrational

\footnotetext{
${ }^{2}$ This finding is, of course, subject to the Lucas' critique (Lucas, 1976).
} 
investors on future fundamentals and risk premia.

We begin with the standard asset pricing equation. Let $P_{t}$ and $D_{t}$ be a stock's market price and dividend at the end of period $t$ or accrued over period $t$, respectively. The gross return on the stock between date $t$ and $t+1$ is then given by:

$$
R_{t+1}=\frac{P_{t+1}+D_{t+1}}{P_{t}}-1
$$

One can then show that the stock price is a function of future dividends $D_{t+i}$, the required stock return $R_{t+i}$, and a terminal value:

$$
P_{t}=\sum_{i=1}^{\infty}\left(\prod_{j=1}^{i} \frac{1}{1+R_{t+j}}\right) D_{t+i}+\lim _{T \rightarrow \infty}\left(\prod_{j=1}^{T} \frac{1}{1+R_{t+j}}\right) P_{t+T}
$$

In log-linear form (less a constant) the stock pricing equation can then be written as $:^{3}$

$$
p_{t}=\sum_{i=1}^{\infty} \rho^{i-1}\left[(1-\rho) d_{t+i}-r_{t+i}\right]+\lim _{T \rightarrow \infty}\left(\rho^{T} p_{t+T}\right)
$$

where $\operatorname{logs}$ of variables are denoted by lowercase letters, $r_{t+1}=\log \left(1+R_{t+1}\right)$ and $\rho$ is a parameter of the linearization defined as $\rho \equiv 1 /(1+\exp (\overline{d-p}))$, where $(\overline{d-p})$ is the longrun average $\log$ dividend-price ratio (such that $0<\rho<1$ ) (Campbell et al., 1996). 4

We introduce an equity premium to the pricing equation by deducting the real risk free rate, $r_{t}^{f}$, measured by the real return on a long term government bond, from both dividends and the required stock return. Hence, we can rewrite (3) in terms of excess dividends, $d_{t}^{e}=(1-\rho) d_{t}-r_{t}^{f}$, and excess returns (the equity premium) that compensate investors for holding risky equity instead of alternative safe investments, such as government bonds with long maturities, $r_{t}^{e}=r_{t}-r_{t}^{f}$ :

$$
p_{t}=\sum_{i=1}^{\infty} \rho^{i-1} d_{t+i}^{e}-\sum_{i=1}^{\infty} \rho^{i-1} r_{t+i}^{e}+\lim _{T \rightarrow \infty}\left(\rho^{T} p_{t+T}\right)
$$

Thus, the stock price reflects the discounted value of future excess dividends, an equity premium measured by the discounted value of future excess stock returns, and a terminal value.

\footnotetext{
$3^{3}$ derivation of equation 3 is shown in Appendix A.

${ }^{4}$ Campbell et al. (1996) shows with U.S. data that the average dividend-price ratio has been about $4 \%$ annually, implying $\rho \approx 0.96$.
} 


\subsection{Expectations and asset (mis)pricing}

Following equation (4), today's stock price depends on future, unobservable realizations of fundamental variables and the stock price itself. That means that agents' expectations about the future will determine the current stock price. Following Campbell \& Vuolteenaho (2004) and Brunnermeier \& Julliard (2008), we allow for the possibility that some investors are irrational, and hold subjective expectations at time $t$, denoted by $\tilde{E}_{t}$, about future realizations of $d_{t}^{e}$ and $r_{t}^{e}$. These expectations obtained under the subjective probability measure may deviate from objective expectations $E_{t}$ that are consistent with the rational processing of objective data.5 Nevertheless, both expectations are conditioned on the same information set available at time $t$, as indicated by the subscript on $E$ and $\tilde{E}$. Hence, taking objective and subjective expectations of (4) yields

$$
\begin{aligned}
p_{t} & =E_{t}\left[\sum_{i=1}^{\infty} \rho^{i-1} d_{t+i}^{e}\right]-E_{t}\left[\sum_{i=1}^{\infty} \rho^{i-1} r_{t+i}^{e}\right]+E_{t}\left[\lim _{T \rightarrow \infty}\left(\rho^{T} p_{t+T}\right)\right] \\
& =\tilde{E}_{t}\left[\sum_{i=1}^{\infty} \rho^{i-1} d_{t+i}^{e}\right]-\tilde{E}_{t}\left[\sum_{i=1}^{\infty} \rho^{i-1} r_{t+i}^{e}\right]+\tilde{E}_{t}\left[\lim _{T \rightarrow \infty}\left(\rho^{T} p_{t+T}\right)\right],
\end{aligned}
$$

respectively. Since both rational and irrational investors are indifferent to marginal changes to their investment, the equality of equations (5) and (6) holds and the current observed stock price is equal to their expected future excess dividends and equity premia. However, expectations about the paths of both variables might differ between both types of investors. This means, for example, that irrational investors who require a high risk premium, $\tilde{E}_{t}\left[r_{t+i}^{e}\right]$, also expect to receive higher excess dividends in the future, $\tilde{E}_{t}\left[d_{t+i}^{e}\right]$. Yet, when irrational investors are present, the observed price $p_{t}$ may deviate from its true fundamental value. This is correctly observed by rational investors who, on average, form correct expectations about future fundamentals $E_{t}\left[d_{t+i}^{e}\right]$ and therefore adjust their required future equity risk premium $E_{t}\left[r_{t+i}^{e}\right]$ such that their stock holdings are in equilibrium. This change in $E_{t}\left[r_{t+i}^{e}\right]$ then ensures that (5) and (6) hold at the observed price level (Brunnermeier \& Julliard, 2008).

By adding and subtracting $\left(E_{t}\left[\sum_{i=1}^{\infty} \rho^{i-1} d_{t+i}^{e}\right]-E_{t}\left[\sum_{i=1}^{\infty} \rho^{i-1} r_{t+i}^{e}\right]\right)$ from (6), we observe that the stock price $p_{t}$ can be written as the sum of three components: a fundamental component, $p_{t}^{F}$, measured by the discounted value of expected future excess dividends, an equity premium, $e p_{t}$, measured by the discounted value of expected future excess stock returns,

\footnotetext{
${ }^{5}$ For a further elaboration on this concept, see Manski (2004) and Brunnermeier \& Parker (2005).
} 
and a mispricing component, $\psi_{t}$ :

$$
p_{t}=\underbrace{E_{t}\left[\sum_{i=1}^{\infty} \rho^{i-1} d_{t+i}^{e}\right]}_{p_{t}^{F}}-\underbrace{E_{t}\left[\sum_{i=1}^{\infty} \rho^{i-1} r_{t+i}^{e}\right]}_{e p_{t}}+\psi_{t},
$$

where $\psi_{t}$ is defined as:

$$
\psi_{t}=\left(\tilde{E}_{t}-E_{t}\right)\left[\sum_{i=1}^{\infty} \rho^{i-1} d_{t+i}^{e}\right]-\left(\tilde{E}_{t}-E_{t}\right)\left[\sum_{i=1}^{\infty} \rho^{i-1} r_{t+i}^{e}\right]+\tilde{E}_{t}\left[\lim _{T \rightarrow \infty}\left(\rho^{T} p_{t+T}\right)\right] .
$$

Thus, the observed stock price $p_{t}$ deviates from its objectively justified fundamental value when (i) irrational investors are present, whose subjective expectations deviate from objective expectations of rational investors; or (ii) the transversality condition under the subjective measure does not hold, i.e. $\tilde{E}_{t}\left[\lim _{T \rightarrow \infty}\left(\rho^{T} p_{t+T}\right)\right] \neq 0$. If one assumes, however, that all agents form expectations under the objective probability measure, which excludes the presence of irrational investors with subjective expectations from the model, mispricing would be represented as a violation of the transversality condition under objective expectations, i.e. $\psi_{t}=E_{t}\left[\lim _{T \rightarrow \infty}\left(\rho^{T} p_{t+T}\right)\right]$. Thus, only if all investors are of the rational type and $\psi_{t}$ is non-zero, mispricing occurs due to the existence of a rational bubble and investors are fully aware of it ${ }^{6}$ Without these restrictive assumptions, however, mispricing can result from false subjective expectations of investors. This is in line with Adam et al. (2015), who also show that subjective belief dynamics can temporarily delink stock prices from their fundamental value and give rise to asset price booms.7 As such, the concept presented here is less restrictive than the one described by Galí (2014) and Galí \& Gambetti (2015), who explain mispricing entirely with the presence of a rational bubble.

\subsection{Effects of monetary policy on stock prices}

In this section, we assess the expected effect of a contractionary monetary policy shock on the identified stock price components from theoretical and previous empirical evidence.

Economic theory points to a decrease of the fundamental component of stock prices in response to a contractionary monetary policy shock for two reasons: First, a monetary tightening decreases future economic growth and, by this, also firms' profits and future dividend pay-outs. Moreover, since inflation is likely to decrease following the contractionary

${ }^{6}$ For example, this can be explained in the context of overlapping generations models (see the survey of Stiglitz (1990) for a larger discussion) or in the context of intrinsic bubbles, as introduced by Froot \& Obstfeld (1991). ${ }^{7}$ For a further extensive survey on the literature relating speculative behavior to irrational and behavioral factors, see Scherbina (2013). 
policy shock and nominal interest rates rise, real risk-free rates also rise Bernanke \& Kuttner, 2005). However, an opposing prediction could be obtained if the monetary policy surprise provides new information to market participants who are less informed about future output and inflation than the central bank. A monetary policy tightening may then signal higher expected future economic growth and, thus, lead to an upward revision of market participants' expectations about future excess dividends. However, we assume that market participants and the central bank share the same information set. In effect, we thus identify monetary policy shocks that can be interpreted as standard Taylor-rule type shocks. Moreover, by restricting excess dividends to fall following a contractionary monetary policy shock, we also offer fundamental variables the best chance to explain a possible decrease in stock prices. As a result, the fundamental component is predicted to fall in response to a contractionary monetary policy shock: ${ }^{8}$

$$
\frac{\partial p_{t+k}^{F}}{\partial \varepsilon_{t}^{m}}=\left[\sum_{i=1}^{\infty} \rho^{i-1} \frac{\partial E_{t}\left(d_{t+k+i}^{e}\right)}{\partial \varepsilon_{t}^{m}}\right]<0
$$

The second channel through which a monetary policy shock propagates to stock prices is through its effects on the expected equity risk premium. The expected equity premium is likely to rise following an exogenous monetary tightening for two reasons. First, there is evidence for a (non-linear) financial accelerator mechanism of monetary policy via balance sheet effects of firms and banks, which implies that monetary tightening is associated with higher borrowing costs and reduced loan supply. In effect, this increases the risk of lower future firm profits. Importantly, the increase in risk can be expected to be larger during times of already tight monetary policy when loan supply is already low and firms' financial health is poor, which calls for a modelling strategy that accounts for this time-variation (Patelis, 1997). Second, as outlined by Gust \& López-Salido (2009), a contractionary monetary policy shock may not only lower future consumption of households but also increases consumption volatility, which would result in a higher equity risk premium required by investors today. Hence, an exogenous monetary tightening can be expected to raise the equity premium that rational investors require to be compensated for the increase in risk:

$$
\frac{\partial e p_{t+k}}{\partial \varepsilon_{t}^{m}}=\left[\sum_{i=1}^{\infty} \rho^{i-1} \frac{\partial E_{t}\left(r_{t+k+i}^{e}\right)}{\partial \varepsilon_{t}^{m}}\right]>0 .
$$

Since the expected equity risk premium enters the stock pricing equation negatively, this further lowers the current stock price. Therefore, in absence of a mispricing component, a contractionary monetary policy shock would induce an immediate fall in stock prices through

\footnotetext{
${ }^{8}$ We allow for a positive response of expected excess dividends in a later robustness check.
} 
both the fundamental and the risk channel.

As for the third channel, the response of the mispricing component $\psi_{t}$ is open to debate. The conventional view of LATW policy proponents builds on the notion that (excessive) stock prices typically fall in response to a contractionary monetary policy shock. In a similar vein, a monetary loosening should therefore propagate stock overpricing. This claim finds empirical support from e.g. Borio \& Lowe (2002), who argue that accommodative monetary policy may, in a low-inflationary environment, stimulate asset price bubbles. Similarly, Bordo \& Landon-Lane (2013) find that several measures of loose monetary policy can be consistently related to periods that are demarcated as asset price booms, even when controlling for other explanatory variables such as credit and current account imbalances. However, these papers are silent about whether the observed asset price boom is driven by fundamental and risk factors or by mispricing, and therefore do not allow for drawing any conclusions on the justification for a LATW monetary policy. Here, the findings of Adam et al. (2015) provide some first tentative evidence that a contractionary monetary policy shock may help to attenuate excessive stock price behavior. The authors find that about two-thirds of the fluctuations in U.S. stock prices are not due to fundamental factors, but result from self-reinforcing beliefs in the sense that agents become more optimistic (pessimistic) about future capital gains whenever they are positively (negatively) surprised by past capital gains. A positive (negative) capital gains surprise in the previous period then increases (decreases) optimism about capital gains associated with investing in the asset today and leads to an asset price boom (bust). Thus, this result indicates that an unexpected decrease in capital gains in response to a contractionary monetary policy shock would lead to a downward correction of the excessive stock price component.

However, the view that contractionary monetary policy helps to reduce excessive stock prices is questioned by Galí (2014). If all investors are fully rational and form objective expectations about the future, mispricing may only occur in the form of a rational bubble. In this case, the bubble component must grow at the required rate of return on stocks in expectation. Thus, since both the risk-free interest rate and the expected equity premium are predicted to increase in response to a contractionary policy shock, an increase in the policy rate will also raise the expected long-run growth rate of the bubble component. This holds, however, only in expectation for each period after the policy shock. On impact, the response of a rational bubble component is, in fact, indeterminate. ${ }^{9}$ However, Galí (2014) disregards that mispricing may also occur from the presence of irrational investors.

Thus, the impact of monetary policy shocks on the stock mispricing component seems to depend on how investors form their expectations and is therefore not only indeterminate ${ }^{9} \overline{\text { See Galí (2014) for a discussion of this issue. }}$. 
on impact but also in the long run, i.e.:

$$
\frac{\partial \psi_{t+k}}{\partial \varepsilon_{t}^{m}}=\left[\sum_{i=1}^{k} \rho^{i-1}\left(\tilde{E}_{t}-E_{t}\right) \frac{\partial d_{t+i}^{e}}{\partial \varepsilon_{t}^{m}}\right]-\left[\sum_{i=1}^{k} \rho^{i-1}\left(\tilde{E}_{t}-E_{t}\right) \frac{\partial r_{t+i}^{e}}{\partial \varepsilon_{t}^{m}}\right]+\tilde{E}_{t}\left[\frac{\partial \rho^{T} p_{t+k}}{\partial \varepsilon_{t}^{m}}\right]=?
$$

To summarize, the responses of the fundamental component and of the equity risk premium to a contractionary monetary policy shock predict an immediate fall in the stock price. However, monetary policy may also affect stock prices via a response of the mispricing component. The direction of change induced through this channel is ambiguous though. As a result, the total response of stock prices to a monetary policy shock ultimately depends on the nature and the importance of the mispricing component relative to the stock's fundamentals, which might vary over time. Hence, in our empirical analysis of monetary policy effects on stock prices, we need to opt for a flexible modeling strategy to allow for time-variation in the estimated model coefficients.

\section{Empirical model and identification}

This section describes the empirical model employed to evaluate to what degree the response of stock prices to monetary policy shocks can be attributed to expected changes in fundamental factors and the risk premium, and how much may be due to stock mispricing. By simple accounting, the response of the mispricing component can be obtained by deducting the implied response paths of the expected fundamental component and the expected equity premium from the observed total response of asset prices following (7) similar to Galí \& Gambetti (2015).

We identify monetary policy shocks in a standard monetary VAR model augmented by stock prices, expected excess dividends and the expected equity premium. We rely on evidence from a constant coefficient VAR and a time-varying coefficient (TVC) VAR. The motivation for the latter is threefold. First, and most importantly, time-variation in the response of stock prices to monetary policy shocks may occur when the reaction of the individual price components differ in size or sign and their relative weights in the total stock price change over time. Second, as outlined in the previous section, we also suspect nonlinearities in the relationship between measures for the business cycle, the policy rate, and our measure for the expected equity risk premium following the discussion in Patelis (1997) and Gust \& López-Salido (2009). Therefore, independent of strong empirical evidence for timevarying coefficients, our model framework suggests the need for such an assessment. Finally, the TVC-VAR has the general advantage that it allows for accounting for structural breaks

and smooth structural change in the model coefficients. Since the constant coefficient VAR 
is a limiting case of the TVC-VAR, as described below, we will only outline the specifications of the TVC-VAR.

\subsection{Time-varying coefficient VAR}

Our reduced form TVC-VAR follows closely that in Primiceri (2005) and Galí \& Gambetti (2015). The dynamic relations between the variables are described by the measurement equation:

$$
Y_{t}=\Theta_{0, t}+\Theta_{1, t} Y_{t-1}+\cdots+\Theta_{p, t} Y_{t-p}+u_{t}
$$

where $Y_{t}$ is the $K \times 1$ vector of endogenous variables. The variables included in the VAR are, first, a measure of output growth $y_{t}$, inflation $\pi_{t}$, and the policy variable $i_{t}$ (federal funds rate) as motivated by the standard class of New-Keynesian models used to identify the Taylor-rule type monetary policy shocks 10 Following our partial equilibrium asset pricing model, we further add the growth rate in real stock prices $p_{t}$, and measures for the expected excess dividend $E_{t}\left[d_{t+k}^{e}\right]$ and the expected equity risk premium $E_{t}\left[r_{t+k}^{e}\right]$ to the set of variables ${ }^{11}$ We specify the model with $p=3$ lags of endogenous variables. ${ }^{12}$ The reduced-form residuals $u_{t}$ are assumed to be independently and normally distributed with variance-covariance matrix $H_{t}$, i.e. $u_{t} \sim N\left(0, H_{t}\right)$. The time-varying coefficients in $\Theta_{i, t}, i=0,1, \ldots, p$, evolve according to a driftless random walk. This is given by the state equation on the joint $m \times 1$ ( $m=$ $K(K p+1))$ vector $\theta_{t}=\operatorname{vec}\left(\left[\Theta_{0, t}, \Theta_{1, t}, \ldots, \Theta_{p, t}\right]\right)$ :

$$
\theta_{t}=\theta_{t-1}+\eta_{t}
$$

Here, $\eta_{t} \sim N(0, Q)$ is a random vector, independent of $u_{t}$ for all periods $t$ and $s$.

The model allows for heteroscedasticity in the reduced-form residuals. To model changes in volatility, a triangular decomposition of the covariance matrix $H_{t}$ of $u_{t}$ is used, given by:

$$
H_{t}=A_{t}^{-1} \Sigma_{t} \Sigma_{t}^{\prime}\left(A_{t}^{-1}\right)^{\prime}
$$

where $\Sigma_{t}$ is a diagonal matrix with elements $\sigma_{i, t}$ for $i=1, \ldots, K$ and $A_{t}$ is lower triangular with diagonal elements equal to one. The dynamics of covariances are governed by:

$$
\alpha_{t}=\alpha_{t-1}+\omega_{t},
$$

\footnotetext{
${ }^{10}$ The responses of asset prices and the underlying fundamentals are robust with respect to including variables typically employed to capture expected inflation, such as commodity prices and non-energy commodity prices. Therefore, these are excluded in order to reduce the computational burden.

${ }^{11}$ In the following, the variables are ordered as $Y_{t}=\left[y_{t}, \pi_{t}, E_{t}\left[d_{t+k}^{e}\right], E_{t}\left[r_{t+k}^{e}\right], i_{t}, p_{t}\right]^{\prime}$.

${ }^{12}$ The findings are robust to varying lag lengths of $p=4$ lags as employed by Galí \& Gambetti (2015).
} 
where $\alpha_{t}=\left[a_{21, t}, \ldots, a_{K(K-1), t}\right]^{\prime}$ captures the non-zero and non-unity elements of $A_{t}$ and $\omega_{t} \sim N(0, W)$, with $W$ being block-diagonal 13 Finally, the dynamics of $\Sigma_{t}$ are modeled according to a stochastic volatility framework, such that:

$$
\ln \left(\sigma_{i, t}\right)=\ln \left(\sigma_{i, t-1}\right)+\nu_{i, t}
$$

with the vector $\nu_{t}=\left[\nu_{1, t}, \ldots, \nu_{K, t}\right]^{\prime}$ being distributed as $\nu_{t} \sim N(0, V)$, where $V$ is diagonal. The TVC-VAR nests the VAR with constant coefficients if the variance matrices $Q, V$, and $W$ shrink to zero. The choice of prior distributions is briefly specified in Appendix $\mathrm{B}$ and follows Galí \& Gambetti (2015).

Finally, our core interest lies in the structural shocks $\varepsilon_{t}$. These underlying shocks govern the dynamics of the reduced form innovations $u_{t}$, which are henceforth assumed to be a linear transformation of $\varepsilon_{t}$ given by $u_{t}=S_{t} \varepsilon_{t}$, where $E\left[\varepsilon_{t}\right]=0, E\left[\varepsilon_{t} \varepsilon_{t-j}^{\prime}\right]=0$ for all $t$ and $j \neq 0$ and $E\left[\varepsilon_{t} \varepsilon_{t}^{\prime}\right]=I_{K}{ }^{14}$ Furthermore, $S_{t}$ is such that $S_{t} S_{t}^{\prime}=H_{t}$. We identify $S_{t}$ as outlined in the next subsection. With the identified $S_{t}$, we then obtain local approximations of the implied dynamic impulse response functions to the period $t$ structural shocks $\varepsilon_{t}$ Galí \& Gambetti, 2015).

\subsection{Identification via sign restrictions}

One important conclusion that one can draw from Galí \& Gambetti (2015) is that their empirical results are not robust to the assumptions used to identify the monetary policy shock. Specifically, the authors obtain diametrically opposing results on the effect of monetary policy shocks on stock prices depending on whether they assume that the central bank reacts contemporaneously, i.e. within the quarter, (by a constant, calibrated coefficient) to stock price surprises or not at all (as in the recursive identification setting). This simultaneity problem in identifying monetary policy shocks in the presence of financial variables is commonly known in the literature. Bjørnland \& Leitemo (2009) provide a solution to this issue by employing a long-run restriction on the real effects of monetary policy shocks. However, for our framework with three financial and forward-looking variables, an even less restrictive identification scheme is required. Consequently, we build on the strategy of Bjørnland \& Leitemo (2009), but further relax the contemporaneous impact restrictions of the recursive identification scheme where needed. To achieve identification we then augment the frame-

${ }^{13}$ Assuming block-diagonality implies that covariances across equations evolve independently from each other. This simplifies inference and drastically increases the efficiency of the estimation algorithm (Primiceri, 2005).

${ }^{14}$ All random vectors $\varepsilon_{t}$ that $\eta_{t}, \nu_{t}$ and $\omega_{t}$ are assumed to be independent of each another. This restriction reduces the number of coefficients that need to be estimated and allows a structural analysis of the shocks $\varepsilon_{t}$ which would be precluded if block elements in the covariance matrix of the vector $\left[\varepsilon_{t}, \eta_{t}, \nu_{t}, \omega_{t}\right]^{\prime}$ were non-zero (Primiceri, 2005). 
work by imposing as many additional restrictions on the data as we can defend from the theoretical considerations discussed in Section 2 and from exogenous empirical evidence (Kilian \& Murphy, 2012). This can be implemented by employing sign restrictions on the impact responses (Fry \& Pagan, 2011).15 Thus, we allow for two-way contemporaneous responses between stock prices, the policy rate, and both expectation measures, and by this we nest all alternative calibrations of the contemporaneous response of monetary policy to stock prices shocks of Galí \& Gambetti (2015). Work by Arias et al. (2014) and Binning (2013) allows us to combine sign restrictions with zero impact and long-run restrictions. ${ }^{16}$

Table 1: Identifying restrictions

\begin{tabular}{c|cccc}
\hline \hline & & & Shock & \\
\hline Variable & $\varepsilon_{t}^{d}$ & $\varepsilon_{t}^{s}$ & $\varepsilon_{t}^{m}$ & 0 \\
\hline$y_{t}$ & + & - & 0 & 0 \\
$\pi_{t}$ & + & + & 0 & $?$ \\
$E_{t}\left[d_{t+k}^{e}\right]$ & $?$ & $?$ & - & $?$ \\
$E_{t}\left[r_{t+k}^{e}\right]$ & $?$ & $?$ & + & $?$ \\
$i_{t}$ & + & $?$ & + & + \\
$p_{t}$ & + & $?$ & $?$ & + \\
\hline \hline
\end{tabular}

The table shows the restricted sign of the impact responses of the variables in the benchmark VAR to a monetary policy shock $\varepsilon_{t}^{m}$, a stock price shock $\varepsilon_{t}^{p}$, as well as to a demand $\left(\varepsilon_{t}^{d}\right)$ and a supply $\left(\varepsilon_{t}^{s}\right)$ shock. The monetary policy shock is further restricted not to affect the real variables $y_{t}$ and $p_{t}$ in the long-run. Entries denoted with by a "?" are left unconstrained.

Our identifying assumptions on the impact responses of the variables in the VAR to four identified shocks are summarized in Table 1. We assume that output and inflation do not respond within the same quarter to a (contractionary) monetary policy shock $\left(\varepsilon_{t}^{m}\right)$. This assumption features strongly in the literature on identifying monetary policy shocks and mirrors the restrictions implied in the Cholesky decomposition (cf. Christiano et al., 2005), which are largely motivated by the perception that the transmission of monetary policy interventions to the real economy is only effective with a considerable lag (Friedman, 1968$),{ }^{17}$ In contrast, all expectations and financial variables are allowed to respond immediately. The imposed signs are motivated by the theoretical predictions developed in Section 2; Expected

15 An alternative could be to employ the external instruments approach of Gertler \& Karadi (2015). This approach is, however, not yet established in the time-varying coefficients VAR literature.

${ }^{16} \mathrm{~A}$ limitation to our approach may be that our prior assumptions on the decomposition and time evolution of the variance-covariance matrix of residuals (equations (14)-(16)) is not fully agnostic and thus may fail to identify all admissible structural models. A solution to this limitation is unfortunately outside the scope of this paper. We thank Prof. Rubio-Ramirez for helpful consultations on this matter.

${ }^{17}$ For a robustness check, we have relaxed the zero impact restrictions, replacing them with sign restrictions that allow the contractionary monetary policy shock (both conventional and unconventional) to lower both output and inflation on impact (Baumeister \& Benati, 2013). The reduction of output growth detected in this case is stronger, while the responses of stock prices and its components remain unaffected. 
excess dividends decrease on impact while the expected equity premium increases ${ }^{18}$ Stock prices are also allowed to respond, yet the sign of the response is ambiguous, allowing for a strong positive response of the mispricing component.

Following Bjørnland \& Leitemo (2009), we interpret a stock price shock $\left(\varepsilon_{t}^{p}\right)$ either as a non-fundamental, idiosyncratic shock motivated by speculative behavior, or as news about future real economic fundamentals. Therefore, expectations and financial variables may respond immediately to the arrival of new fundamental information or simply due to portfolio re-balancing in view of higher realized capital gains. The sign of their responses is left unconstrained with the obvious exception of stock prices. Similar to the case of the monetary policy shock, we assume that a stock price shock has no immediate effect on the slow moving variables output and inflation. This identification, therefore, distinguishes idiosyncratic stock price shocks from general demand or supply shocks. This is at the heart of the discussion regarding how central banks should react to stock price shocks that are not immediately related to their primary targets of inflation and output, but may only affect those variables in the longer run. Yet, this leaves us with the simultaneity problem in distinguishing stock price and monetary policy shocks, as they are not uniquely identified so far. We solve this by imposing additional long-run restrictions on the monetary policy shock following Bjørnland \& Leitemo (2009). Specifically, we assume that monetary policy does not have any permanent effect on the real variables output and stock prices by the long-run neutrality of money.

Finally, we attempt to identify general aggregate demand $\left(\varepsilon_{t}^{d}\right)$ and supply shocks $\left(\varepsilon_{t}^{s}\right)$. Even though we are not primarily interested in those shocks, imposing as many restrictions as possible helps to close in on the shocks of interest and discard implausible models (cf. Canova \& Gambetti, 2009 and Kilian \& Murphy, 2012). The imposed impact restrictions displayed in the table are standard in the literature and follow Baumeister \& Benati (2013). Following the previous discussion on the nature of a stock price shock, a general demand or supply shock is hence characterized by immediate responses of output and inflation.

\section{Data}

Our analysis builds on sample information from 1962Q1 to 2014Q4. In our benchmark analysis we do not exclude the financial crisis period but rely on our TVC model to account for possible structural breaks and smooth structural changes in the parameters. The variables included in the VAR are real GDP, the GDP deflator (both in log-growth rates), the effective

\footnotetext{
${ }^{18}$ However, for a robustness check, we also allow for the possibility that market participants revise their expectations about excess dividends upwards following the signal of a contractionary monetary policy shock. In this case, we leave the response of expected excess dividends unconstrained.
} 
federal funds rate and the growth rate of the real S\&P500 index. ${ }^{19}$ All series are deflated by the U.S. Consumer Price Index for All Urban Consumers. Further, we add the two measures for expected excess dividends, $E_{t}\left[d_{t+k}^{e}\right]$, and and expected excess return on stocks, $E_{t}\left[r_{t+k}^{e}\right]$, (the expected equity risk premium). These variables are, however, not observable.

To obtain a proxy for both expectations, we therefore follow the a broad literature initiated by Campbell (1991), which is also employed by Bernanke \& Kuttner (2005) and Brunnermeier \& Julliard (2008), and use an auxiliary VAR model to forecast the objective expectations of $d_{t+k}^{e}$ and $r_{t+k}^{e}$ at each margin $t$. The forecast $\hat{d}_{t+k}^{e}$ and $\hat{r}_{t+k}^{e}$ from the VAR can then be interpreted as the objective expectations $E_{t}\left[d_{t+k}^{e}\right]$ and $E_{t}\left[r_{t+k}^{e}\right]$ consistent with the rational processing of data in line with equation (7) of our model framework. The variables included in the auxiliary VAR model are realized log dividends and the realized quarterly stock return $r_{t}$, and the risk free rate measured by the 10-year U.S. government bond rate. From the forecasted series of these variables, we obtain our measures for expected excess dividends and the equity risk premium. Additionally, we add the log price-earnings ratio, $p_{t}-e_{t}$, and the BAA-AAA corporate bond spread, $r_{t}^{b}$, as important predictors for future stock returns and equity risk (Campbell et al., 2013).20 Here, the corporate bond spread serves as an exogenous measure for expected default risk in the economy, which is likely to be correlated with the expected equity risk premium 21 The lag length of the VAR is set to one and the forecasts are obtained from a VAR estimated on the full sample in line with the literature (Campbell, 1991; Bernanke \& Kuttner, 2005; Brunnermeier \& Julliard, 2008; Campbell et al., 2013). Finally, the forecast horizon is set to ten years to relate expected excess equity returns to the yields on the long-maturity government bond. 10-year forecasts are obtained sequentially for each quarter 22

Figure 1 shows the ten-year forecasts of excess dividends and equity returns over time, which we interpret as the rational expectations at each point in time. In line with evidence in Claus \& Thomas (2001), we find an expected equity premium of around three percent, which fluctuates, however, quite substantially over time. We find an increase in the expected premium simultaneous with the rise in real interest rates during the Volcker-disinflation period until about 1984. Subsequently, the expected premium has decreased back to the level of the early 1960's, during the Great Moderation. From 1995 onwards, the expected

${ }^{19}$ Data is obtained from Federal Reserve Economic Data (FRED) of the Federal Reserve Bank of St. Louis, available at http://research.stlouisfed.org/fred2/, and from Shiller (2005), available at http://www. econ.yale.edu/ shiller/data.htm.

${ }^{20}$ Earnings $e_{t}$ are the 10-year moving average of quarterly earnings from Shiller (2005).

${ }^{21}$ The forecasts are robust to additional variables frequently used in the literature, such as the term spread measured by the difference between the 10-year U.S. treasury bond and the 3-month treasury bill yield (Campbell et al. 2010) and a measure for expected market volatility obtained from the quarterly variance of daily returns (Campbell et al., 2012).

${ }^{22}$ Our results are robust to lowering the forecast horizon (and thus the implied average stock-holding period) to five years. 
equity risk premium declined rapidly further, contemporaneous to the sharp run-up in stock prices during the dot-com bubble. During the collapse of the bubble in the early 2000s, the expected premium jumped up again. In fact, the initial rise in the expected equity premium precedes the dot-com crash in 2000Q1. Finally, the expected equity premium spiked once more, but this time subsequently to the collapse of the housing bubble.

In contrast to the expected equity premium, expectations on excess dividends are relatively stable until about 2003. Thereafter they increased strongly with the exception of the period around the global financial crisis in 2008. This suggests that the stock price boom of the dot-com bubble can be explained by a fall in the required equity premium rather than by rising expectations about future excess dividends, whereas the observed rise in stock prices at the end of the sample can be explained by a combination of both components. Since the expected excess dividends series is found to be non-stationary, this variable enters our (TVC-)VAR in log-differences.

[Figure 1 about here.]

As a robustness check, we compare our measure of the expected equity risk premium with two alternative proxies of expected default or equity risk commonly used in the literature. The first is the BAA-AAA spread, which measures the expected default risk premium in the corporate bond market and should therefore be correlated with expected risks on equity. The second measure is derived from the Gordon (1962) dividend discount model (DDM), which suggests to infer the implied required rate of return on stocks directly from the asset pricing equation (2) (Claus \& Thomas, 2001) ${ }^{23}$ This model is, however, not consistent with our framework as it excludes the possibility of asset mispricing and assumes that the transversality condition holds at all times. Therefore, we only employ it as a robustness check of our proxy of the expected equity premium, and presume a positive correlation between the two measures in case mispricing is only weak or restricted to some periods.

We find that our measure of the expected equity premium derived from the auxiliary VAR model is strongly correlated with both the BAA-AAA spread (correlation of 0.64) and the measure derived from the DDM (correlation of 0.49). Figure 2 plots the three (standardized) measures for expected risk premia. The figure shows that the trend in all proxies is similar, with rising expected premia until about 1985, a following downward trend, and a

${ }^{23}$ With a measure of the expectations about future real cash flows and under the additional assumption that the time $t$ required return remains constant in the future, one can infer $E_{t}\left[R_{t+1}\right]=E_{t}\left[R_{t+2}\right]=\ldots$ from 22. Along those lines, we obtain annual estimates of the DDM implied equity premium from Damodaran (2015). These estimates are then transformed to the quarterly frequency using the BAA-AAA default spread. Specifically, we compute the ratio of the DDM equity premium and the annual average of the default spread. Assuming that this ratio remains constant over one year, the spread-adjusted DDM equity premium can then be obtained as the average quarterly BAA-AAA spread multiplied by that ratio. 
strong spike around the global financial crisis. However, the downward trend of the expected equity premium obtained from our auxiliary VAR is more pronounced during the dot-com bubble and the rise during the financial crisis is less strong compared to the other two measures. Further, our preferred measure appears less erratic overall. The frequent sharp rises and falls in the DDM premium may reflect the fact that it is potentially distorted by the presence of stock mispricing.

[Figure 2 about here.]

Given our measure for the rational expectations on excess dividends, the equity premium and the observations for total stock prices, we can evaluate the implied mispricing component contained in the S\&P500. For this, we first discount at each margin $t=1, \ldots, T-h$ the next $h$ realizations of excess dividends and our measure for the expected equity premium. From equation (7), we can then obtain $\psi_{t}=p_{t}-\left(E_{t}\left[\sum_{i=1}^{\infty} \rho^{i-1} d_{t+i}^{e}\right]-E_{t}\left[\sum_{i=1}^{\infty} \rho^{i-1} r_{t+i}^{e}\right]\right)$, where we approximate the infinite sum by the next $h=20$ realizations ${ }^{24}$ The approximated mispricing component is displayed alongside the log real S\&P500 and the implied risk-adjusted fundamental component (the sum of future discounted excess dividends less the sum of future discounted expected equity premia) in Figure 3.

[Figure 3 about here.]

Importantly, the level of mispricing is indeterminate due to the omitted constant in equation (7). Nonetheless, the figure allows us to evaluate the evolution of the mispricing component relative to the dynamics of the log real S\&P500 index. Thus, the figure reveals some time variation in the contributions of the risk-adjusted fundamental and the mispricing components to the overall stock price. Up to 1982, the size of the risk-adjusted fundamental component exhibits a steady downward trend while stock prices fluctuated more widely, first showing an upward trend until 1975 and then starting to decrease thereafter. Thus, most of the short-run dynamics of the stock price index can be attributed to a volatile mispricing component. From 1982 onwards, both the fundamental and the mispricing component increase and contributed to the pronounced increase in the overall stock index. Yet, around 1986 - prior to the 1987 stock market crash - the trend growth in the S\&P500 decouples from the relatively stable evolution of the fundamental component and is thus largely attributed to a strong increase in the mispricing component. This is again the case during the run-up to and the crash of the dot-com bubble in the second half of the 1990's and the early 2000s. Thus, our measure of the mispricing component coincides well with anecdotal evidence of

\footnotetext{
${ }^{24}$ The implied mispricing is robust to extending the approximation of the infinite sum to $h>20$ observations.
} 
excessive stock price periods.

In the following, we, however, refrain from using the estimated mispricing component directly in our VAR model and instead infer the impulse response of the mispricing component to a monetary policy shock from the responses of the observed stock price index, and of the expectations about future excess dividends and excess equity returns. This allows a comparison of our results with those of Galí \& Gambetti (2015), who follow a similar approach. However, we find that our results are robust to including the estimated mispricing component in the VAR instead of the observed stock price index, and estimating the mispricing response directly.

\section{Results}

We first present the estimated responses of the stock price and its components to a contractionary monetary policy shock in the framework of a constant coefficient VAR (C-VAR), which can be estimated more efficiently than the TVC-VAR ${ }^{25}$ Later, we move to TVC-VAR estimations and show that there is some evidence for time-variation in the responses of stock prices and expected equity premia to monetary shocks. The TVC-VAR supports the general findings from the C-VAR. The monetary policy shock is calibrated to raise the policy rate by 100 basis points (BPS). The individual stock price components are calculated as suggested by our stock price equation (7), where we approximate the infinite sum of discounted excess dividends and expected equity premia by the sum over the next 20 periods.

\subsection{Evidence from a constant coefficient VAR}

Figure 4 shows the cumulative impulse responses of the financial variables and the inferred responses of the individual stock price components. In detail, panel 1-3 show the responses of the variables that enter our VAR model, i.e. the measures for expected excess dividends and the risk premium, as well as the real S\&P500 price index. To explore the explanatory contribution of the fundamental components to the total stock price response to a monetary policy shock, we display the response of the three individual stock price components as inferred from equation (7) in panels 4-6. In particular, we assess the impulse responses of the fundamental component, measured as the expected sum of future discounted excess dividends, the fundamental component adjusted for the expected sum of future discounted

${ }^{25}$ We estimate both models with Bayesian methods using the Gibbs sampler. To approximate the posterior distribution of the C-VAR we obtain 10,000 draws (after a burn-in of 5,000 draws) of which we retain every fifth to remove potential serial correlation. For the TVC-VAR, we increase the burn-in to 10,000 draws and approximate the posterior by every fifth of 25,000 draws. In both models, we obtain the admissible set of impulse responses by assessing 1,000 candidate impact response matrices to fulfill the zero and sign restrictions for each draw of the reduced form parameters using the algorithm of Binning (2013). 
equity premia (labeled risk-adjusted fundamental component), and, finally, the mispricing component that is obtained by subtracting the response of the risk-adjusted fundamental component from the observed total response of stock prices.

[Figure 4 about here.]

We find that expectations about excess dividends decrease on impact by about three percent and the expected equity risk premium increases by about three BPS. Both responses are significant for at least one year. Further, we find a strong negative response of the real S\&P500 index of about 3.3 percent on impact which is significant for about three years. While our point estimate is smaller in absolute terms than the nine percent estimate of Bjørnland \& Leitemo (2009), their estimate lies well within our posterior error bands. It is worth mentioning that when we repeat our estimations relying on the more restrictive Cholesky identification scheme of Galí \& Gambetti (2015), we cannot replicate the negative response of the stock market index. Hence, we argue that the identification strategy plays an important role in explaining the differences in the estimation results, where ours is less restrictive. However, also the addition of both expectation measures adds to our finding that stock prices are suppressed for a prolonged period after the shock.

Inferred from the response of expected excess dividends, we, similarly to Galí \& Gambetti (2015), find that the fundamental component decreases significantly by about $1.5 \%$ on impact. This decline is persistent and significant throughout. Yet, this response implies that the fundamental factor explains less than half of the immediate decrease in the S\&P500. Subtracting the implied response of the required risk premium, we find that the explanatory content increases further and that the responses in excess dividends and the expected risk premium together account for a 1.7 percent fall in stock prices (panel 5).

Thus, this leaves about half of the observed 3.3 percent impact drop in the S\&P500 index unexplained. From equation (7) this unexplained part can hence be attributed to the response of the mispricing component as displayed in the lower right panel. Consequently, we conclude that a contractionary monetary policy shock systematically lowers stock prices over and beyond what is implied by fundamental factors.

Hence a central bank could use such a policy to lean against the wind of stock price bubbles if it perceives stock prices to be excessively high ${ }^{26}$ This result contrasts the findings of Galí \& Gambetti (2015) and is difficult to align with the theoretical predictions of the rational bubble framework. This further suggests that stock mispricing can be at least partially attributed to beliefs of irrational investors.

${ }^{26} \mathrm{It}$ is important to note that our results are subject to the Lucas' critique. If monetary policy were to exploit these findings in a systematical manner, investors will take this into account, which may already reduce the frequency of excessive stock price periods. 
We assess the robustness of our results along two dimensions. First, our results are robust to relaxing the sign restriction on expected excess dividends. When we allow for a positive response, expected excess dividends do not decrease significantly across the studied impact horizons. Since the response of all other financial variables is unaffected, this implies a smaller response of the fundamental component and thus an even larger negative response of the mispricing component to a contractionary monetary policy shock ${ }^{27}$ Moreover, we also find our results to be largely robust to employing the BAA-AAA spread or the DDM implied equity return as alternative measures for expected excess returns. The results are displayed in Figures 5 and 6. We find a slightly larger response of the approximated expected equity premium of nine BPS for the BAA-AAA spread and seven BPS for the DDM-implied premium compared to the VAR-forecast measure. The response of expected excess dividends is robust to employing these two alternative proxies. However, the total response of the S\&P500 is somewhat stronger at around 3.8 percent when we use the BAA-AAA spread, and the explanatory power of the mispricing component is smaller and only significant at a few horizons. When we employ the DDM implied equity return, however, the total response of the S\&P500 is larger at around eight percent, and this response is explained largely by the response of the mispricing component that falls by about 6.8 percent on impact.

[Figures 5 and 6 about here.]

Our findings suggest that central banks could attenuate excessive stock price developments by raising the policy rate. Yet, in order to assess whether central banks also should make use of such a LATW policy, we need to trade off the benefits of such a policy against its real economic costs. Figure 7 shows the cumulative responses of output and inflation to the exogenous 100 BPS increase in the policy rate (in the top panels). The figure reveals that a leaning against the wind policy lowers output significantly by one percent after one year. Similarly, prices decrease significantly by about one percent in the long-run. Deflating excessively high stock prices through conventional interest rate policy puts considerable downward pressures on real economic activity. In times when excessive stock price behavior is not accompanied by excessive real economic growth and inflation above target, this would indicate a conflict between financial stabilization on the one hand, and price and output stabilization on the other hand. Thus, our result feeds into the debate of whether monetary policy is too blunt an instrument to stabilize asset prices, if not, what other policy instruments, i.e. macroprudential policies, are more suitable for this objective. However, one also has to consider that the immediate costs of lower output and inflation could be offset if the relevant counterfactual is that an emerging bubble is not pricked through active monetary

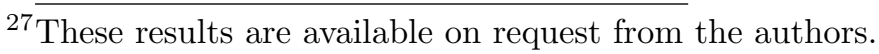


policy, but results in a financial market crash with a potentially larger output and inflation contraction. This, however, cannot be captured and estimated in our modelling framework. ${ }^{28}$

[Figure 7 about here.]

Finally, we also address the question of how the U.S. Fed responded to stock price surprises, which is key for the identifying restriction in Galí \& Gambetti (2015). These results are presented in Figure 8. While there is considerable uncertainty about the Fed's response to stock price shocks that raise the S\&P500 by one percent, we cannot refute that monetary policy has taken a stance of "benign neglect" to stock price surprises (panel 3). However, we find some indication that the Federal Reserve Bank responds by increasing its key interest rate with a considerable delay.

[Figure 8 about here.]

\subsection{Evidence from the TVC-VAR}

Figures 9 to 13 show the responses of excess dividends, the equity premium, stock prices and its decompositions to a 100 BPS contractionary monetary policy shock over time. In general, the TVC-VAR confirms the main findings from our constant coefficient VAR model, but we nevertheless find some time-variation in the impulse responses, which helps shed light on the question of whether a LATW policy is particularly effective during specific periods of time, especially in times of stronger mispricing.

Figure 9 shows that the negative response of expected excess dividends was quite stable over time and increased in absolute terms only toward the end of the sample. For the expected equity risk premium, time variation in the response is more pronounced. Figure 10 shows that until around 1990, the positive response of the expected equity premium was very modest at around five BPS. Thereafter, the response increased considerably up to 20 BPS and became more volatile. Similarly, the response of the stock price index shown in Figure 11 shows a substantial degree of time variation around 1990. Until then, the S\&P500 decreased by around five percent following a monetary tightening of 100 BPS. Thereafter, however, the response increased in absolute value to around 12 percent during the dot-com bubble in the late 1990's and the last quarters in 2014.

[Figures 9, 10 and 11 about here.]

${ }^{28} \overline{\text { For a concluding statement on the cost-benefits-analysis of such a policy, one would need to consider a general }}$
equilibrium model with a loss function of the monetary authority, which is beyond the scope of this paper. 
Correspondingly, also the individual components also respond more strongly during the latter part of the sample. As shown in Figure 12, the impact of the implied risk-adjusted fundamental component continuously strengthened, thus increasing its explanatory power for the decline in stock prices from around two percent in 1980 to around six percent at the end of the sample. Together with the overall stock price response in Figure 11, this implies a time-varying response of the mispricing component only since about 1990. As displayed in Figure 13, we first confirm the negative response of the mispricing component to a contractionary monetary policy over the whole sample, providing strong evidence that the central bank could lower excessive price movements in stocks by raising its policy rate. Yet, we observe that the response has increased sharply in absolute value around 1990 and is particularly strong between 1995 and 2001, the period that is associated with the stock price boom during the dot-com bubble. Our evidence thus suggests, that a tighter monetary policy stance during this period could have reduced mispricing by about seven percent.29

[Figures 12 and 13 about here.]

To summarize, the results of the TVC-VAR offer support to the proponents of a LATW policy and indicate that a monetary tightening lowers excessive stock prices. To give an indication of the significance of this finding, Figure 14 displays the probability of a negative cumulative response of the mispricing component over time at selected horizons from the credible set of accepted impulse responses. For horizons up to one year, this probability is larger than $50 \%$ and takes values of up to $90 \%$ for the impact and one quarter horizons and the time period of up to 1990. Interestingly, however, during the period 1990 to 2001 period, when the S\&P500 was most likely overpriced, a monetary policy contraction would likely have been more effective at attenuating mispricing for horizons of one year or longer, compared to the earlier part of the sample. On impact, the chance of reducing mispricing was larger at the beginning of the sample than toward the end of the sample.

[Figure 14 about here.]

\subsection{Robustness analysis: Monetary policy at the zero lower bound}

In response to the global financial crisis, the Federal Reserve Bank gradually lowered its target range for the federal funds rate until it reached the zero-lower bound (ZLB) in December 2008. From this time onwards, the federal funds rate could no longer be used as an instrument

${ }^{29}$ In contrast to the time-variation in responses of financial variables, the response of output and inflation to monetary policy shocks is relatively stable across time and corresponds to the responses estimated using the C-VAR. 
to further stimulate the economy. To evaluate whether the estimated time-variation in the effects of monetary policy over time was subject to this constraint, we perform two robustness checks. First, and similar to Galí \& Gambetti (2015), we have repeated all estimations on a shorter sample up to 2007Q4, thus excluding the global financial crisis, and find that our results are broadly robust to the shorter sample period ${ }^{30}$ Second, we run our estimations using the $\mathrm{Wu} \& \mathrm{Xia}(2014)$ shadow rate instead of the federal funds rate in our VAR. The shadow rate accounts for unconventional monetary policy effects on the term structure of interest rates in a ZLB environment and is used as a measure of the federal funds rate that would prevail in the absence of the ZLB.

Figures 15 to 19 show the impulse responses of expected excess dividends, the expected equity premium, stock prices, the risk-adjusted fundamental and the speculative component over time. We can generally confirm the previous results obtained for the expected excess dividends and the equity risk premium. However, the impact responses are slightly smaller than in the benchmark model. Moreover, we find that the time-variation in the response of stock prices is now less pronounced (Figures 17 ). In combination, this implies a stronger negative response of the mispricing component in the first part of the sample up until about 1995, and a weaker but still negative response toward the end of the sample. In particular, the dot-com bubble episode no longer stands out. Thus, we can conclude that the policy constraint at the zero lower bound explains part of the observed time variation of the response of the mispricing component of stock prices.

\section{[Figures 15, 16, 17, 18 and 19 about here.]}

\section{Conclusion}

In this paper, we explore the effects of monetary policy on stock prices and its individual components, and, by allowing for the possibility of stock mispricing, we address the question whether central banks could implement a leaning against the wind policy to attenuate excessive stock price developments. For this, we develop a partial equilibrium asset pricing model that allows us to decompose the observed stock price into a fundamental component, a required risk premium and a mispricing component. In our framework, mispricing may arise from wrong subjective believes of irrational investors about the future development of fundamental determinants of stock prices or due to a violation of the transversality condition. We then evaluate how monetary policy affects stock prices through these three components. While theory provides unique predictions for the response of the fundamental component and the expected risk premium, the response of the mispricing component is ambiguous. Hence,

\footnotetext{
${ }^{30}$ Results are available on request.
} 
we attempt to answer this question empirically.

Earlier literature shows that one obtains diametrically opposing results on the response of stock prices and a possible mispricing component depending on whether one assumes that monetary policy reacts contemporaneously or only with a delay to news in stock prices. By adopting a flexible identification scheme of combining zero impact and long run restrictions augmented by sign restrictions, we show that there is a large uncertainty about the actual response of the U.S. Federal Reserve bank to stock price surprises.

Allowing for an active monetary policy in response to a stock price shock, we recover that stock prices decrease significantly and persistently in response to a monetary policy tightening. We then carry out an accounting exercise to distinguish the different channels of how monetary policy affects stock prices. Here, we find that fundamental factors such as a decrease in expected future dividends and an increase in the real interest rate, as well as an increase in the expected equity premium can account for about half of the immediate 3.3 percent fall in stock prices. Hence, we conclude that the other half of the decrease in stock prices can be attributed to a systematic negative response of the mispricing component. By this, we provide support to the claims of proponents of a more active, leaning against the wind monetary policy. If stocks are overpriced, contractionary monetary policy can be used to lower mispricing. However, this comes at the cost of considerable downward pressure on prices and real economic activity.

Therefore, it is debatable whether conventional interest rate policy is the right tool to attenuate excessive stock mispricing at all times or whether interest rates are too blunt a tool to cost-effectively reduce mispricing in stocks. However, as our findings suggest a significant overreaction of stock markets to interest rate shocks, policy makers need to carefully consider financial stability concerns also for accommodative monetary policy measures, as they may induce a significant and persistent overpricing in stock markets, and foster the build-up of imbalances in the financial system. 


\section{References}

Adam, K., Marcet, A., \& Beutel, J. (2015). Stock Price Booms and Expected Capital Gains. Working Papers 757, Barcelona Graduate School of Economics.

Arias, J. E., Rubio-Ramirez, J. F., \& Waggoner, D. F. (2014). Inference Based on SVARs Identified with Sign and Zero Restrictions: Theory and Applications. Working Paper 2014-1, Federal Reserve Bank of Atlanta.

Baumeister, C. \& Benati, L. (2013). Unconventional Monetary Policy and the Great Recession: Estimating the Macroeconomic Effects of a Spread Compression at the Zero Lower Bound. International Journal of Central Banking, 9(2), 165-212.

Bernanke, B. \& Gertler, M. (1999). Monetary Policy and Asset Price Volatility. Economic Review, Q IV, 17-51.

Bernanke, B. S. \& Kuttner, K. N. (2005). What Explains the Stock Market's Reaction to Federal Reserve Policy? The Journal of Finance, 60(3), 1221-1257.

Binning, A. (2013). Underidentified SVAR models: A framework for combining short and long-run restrictions with sign-restrictions. Working Paper 2013/14, Norges Bank.

Bjørnland, H. C. \& Leitemo, K. (2009). Identifying the Interdependence between US Monetary Policy and the Stock Market. Journal of Monetary Economics, 56(2), 275 - 282.

Bordo, M. D. \& Landon-Lane, J. (2013). Does Expansionary Monetary Policy Cause Asset Price Booms; Some Historical and Empirical Evidence. Working Paper 19585, National Bureau of Economic Research.

Borio, C. \& Lowe, P. (2002). Asset Prices, Financial and Monetary Stability: Exploring the Nexus. BIS Working Papers 114, Bank for International Settlements.

Brunnermeier, M. K. \& Julliard, C. (2008). Money Illusion and Housing Frenzies. Review of Financial Studies, 21(1), 135-180.

Brunnermeier, M. K. \& Parker, J. A. (2005). Optimal Expectations. American Economic Review, 95(4), 1092-1118.

Campbell, J. Y. (1991). A Variance Decomposition for Stock Returns. The Economic Journal, 101(405), 157-179.

Campbell, J. Y., Giglio, S., \& Polk, C. (2013). Hard Times. Review of Asset Pricing Studies, 3(1), 95-132.

Campbell, J. Y., Giglio, S., Polk, C., \& Turley, R. (2012). An Intertemporal CAPM with Stochastic Volatility. NBER Working Papers 18411, National Bureau of Economic Research, Inc. 
Campbell, J. Y., Lo, A. W., \& MacKinlay, A. C. (1996). The Econometrics of Financial Markets. Princeton: Princeton University Press.

Campbell, J. Y., Polk, C., \& Vuolteenaho, T. (2010). Growth or Glamour? Fundamentals and Systematic Risk in Stock Returns. Review of Financial Studies, 23(1), 305-344.

Campbell, J. Y. \& Vuolteenaho, T. (2004). Inflation Illusion and Stock Prices. American Economic Review, 94(2), 19-23.

Canova, F. \& Gambetti, L. (2009). Structural Changes in the US Economy: Is there a Role for Monetary Policy? Journal of Economic Dynamics and Control, 33(2), 477-490.

Cecchetti, S. G., Genberg, H., \& Wadhwani, S. (2002). Asset Prices in a Flexible Inflation Targeting Framework. Working Paper 8970, National Bureau of Economic Research.

Christiano, L. J., Eichenbaum, M., \& Evans, C. L. (2005). Nominal Rigidities and the Dynamic Effects of a Shock to Monetary Policy. Journal of Political Economy, 113(1), 1-45.

Claus, J. \& Thomas, J. (2001). Equity Premia as Low as Three Percent? Evidence from Analysts' Earnings Forecasts for Domestic and International Stock Markets. The Journal of Finance, 56(5), 1629-1666.

Cochrane, J. H. (2011). How Did Paul Krugman Get It So Wrong. Economic Affairs, 31(2), 36 40.

Damodaran, A. (2015). Equity Risk Premiums (ERP): Determinants, Estimation and Implications - The 2015 Edition. Technical report, Stern School of Business.

Del Negro, M. \& Primiceri, G. (2013). Time-varying structural vector autoregressions and monetary policy: a corrigendum. Staff Reports 619, Federal Reserve Bank of New York.

Friedman, M. (1968). The Role of Monetary Policy. The American Economic Review, 58(1), 1-17.

Froot, K. A. \& Obstfeld, M. (1991). Intrinsic Bubbles: The Case of Stock Prices. American Economic Review, 81(5), 1189-214.

Fry, R. \& Pagan, A. (2011). Sign Restrictions in Structural Vector Autoregressions: A Critical Review. Journal of Economic Literature, 49(4), 938-60.

Furlanetto, F. (2011). Does Monetary Policy React to Asset Prices? Some International Evidence. International Journal of Central Banking, 7(3), 91-111.

Galí, J. (2014). Monetary Policy and Rational Asset Price Bubbles. American Economic Review, 104(3), 721-52. 
Galí, J. \& Gambetti, L. (2015). The Effects of Monetary Policy on Stock Market Bubbles: Some Evidence. American Economic Journal: Macroeconomics, 7(1), 233-57.

Gertler, M. \& Karadi, P. (2015). Monetary Policy Surprises, Credit Costs, and Economic Activity. American Economic Journal: Macroeconomics, 7(1), 44-76.

Gordon, M. J. (1962). The Investment, Financing, and Valuation of the Corporation. Homewood, Illinois: Richard D Irwin Inc.

Gust, C. \& López-Salido, J. D. (2009). Monetary Policy, Velocity, and the Equity Premium. CEPR Discussion Papers 7388, C.E.P.R. Discussion Papers.

Kilian, L. \& Murphy, D. P. (2012). Why Agnostic Sign Restrictions Are Not Enough: Understanding The Dynamics Of Oil Market Var Models. Journal of the European Economic Association, 10(5), $1166-1188$.

Kilian, L. \& Murphy, D. P. (2014). The Role of Inventories and Speculative Trading in the Global Market for Crude Oil. Journal of Applied Econometrics, 29(3), 454-478.

Lucas, R. J. (1976). Econometric Policy Evaluation: A Critique. Carnegie-Rochester Conference Series on Public Policy, 1(1), 19-46.

Lütkepohl, H. \& Netsunajev, A. (2014). Structural Vector Autoregressions with Smooth Transition in Variances: The Interaction between U.S. Monetary Policy and the Stock Market. Discussion Papers of DIW Berlin 1388, DIW Berlin, German Institute for Economic Research.

Manski, C. F. (2004). Measuring Expectations. Econometrica, 72(5), 1329-1376.

Patelis, A. D. (1997). Stock Return Predictability and The Role of Monetary Policy. The Journal of Finance, 52(5), 1951-1972.

Phillips, P. C. B., Shi, S., \& Yu, J. (2015). Testing for Multiple Bubbles: Historical Episodes of Exuberance and Collapse in the S\&P 500. International Economic Review, 56(4), 1043-1078.

Phillips, P. C. B., Wu, Y., \& Yu, J. (2011). Explosive Behavior in the 1990's NASDAQ: When Did Exuberance Escalate Asset Values? International Economic Review, 52(1), 201-226.

Posen, A. S. (2006). Why Central Banks Should Not Burst Bubbles. International Finance, 9(1), $109-124$.

Primiceri, G. E. (2005). Time Varying Structural Vector Autoregressions and Monetary Policy. The Review of Economic Studies, 72(3), 821-852.

Rigobon, R. \& Sack, B. (2003). The Impact of Monetary Policy on Asset Prices. Journal of Monetary Economics, 51(8), 1553-1575. 
Scherbina, A. (2013). Asset Price Bubbles: A Selective Survey. Working Paper 13/45, International Monetary Fund.

Shiller, R. J. (2005). Irrational Exuberance. Princeton: Princeton [u.a.] : Princeton Univ. Press, 2. ed. edition. Includes bibliographical references and index.

Stiglitz, J. E. (1990). Symposium on Bubbles. Journal of Economic Perspectives, 4(2), 13-18.

Wu, J. C. \& Xia, F. D. (2014). Measuring the Macroeconomic Impact of Monetary Policy at the Zero Lower Bound. Working Paper 20117, National Bureau of Economic Research. 


\section{A Derivation of Equation (3)}

Under the assumption that the price-dividend ratio is stationary, the log-linear approximation of equation (1) is given by:

$$
\begin{aligned}
r_{t+1} & =\log \left(P_{t+1}+D_{t+1}\right)-\log \left(P_{t}\right) \\
& =p_{t+1}-p_{t}+\log \left(1+\exp \left(d_{t+1}-p_{t+1}\right)\right)
\end{aligned}
$$

where logs of variables are denoted by lowercase letters and $r_{t+1}=\log \left(1+R_{t+1}\right)$. $\log$ linearizing equation (17) around the steady state using a first-order Taylor expansion, we obtain:

$$
r_{t+1}=k+\rho p_{t+1}+(1-\rho) d_{t+1}-p_{t}
$$

where $\rho$ and $k$ are parameters of linearization defined as $\rho \equiv 1 /(1+\exp (\overline{d-p}))$, where $(\overline{d-p})$ is the average $\log$ dividend-price ratio (such that $0<\rho<1$ ), and $k \equiv-\log (\rho)-$ $(1-\rho) \log (1 / \rho-1)$.

Solving equation 18 for $p_{t}$ and iterating forward, the stock price can be written (disregarding the the constant term $k$ ) as a linear combination of future dividends, future stock returns, and a terminal value:

$$
p_{t}=\sum_{i=1}^{\infty} \rho^{i-1}\left[(1-\rho) d_{t+i}-r_{t+i}\right]+\lim _{T \rightarrow \infty} \rho^{T} p_{t+T} .
$$

\section{B Priors and estimation}

We follow Primiceri (2005) and Galí \& Gambetti (2015) and assume that the initial states for the coefficients $\theta_{t}$, the covariances $\alpha_{t}$, the $\log$ volatilities $\sigma_{t}$ and the hyperparameters $Q$, $V$ and $W$ are independent of each other. The priors for the initial states of the coefficients, the covariances and the log standard errors are assumed to be normally distributed. The priors of the hyperparameters are assumed to be distributed as independent inverse-Wishart. All these assumptions are standard in the literature as described in Primiceri (2005). The 
priors thus take the specific forms:

$$
\begin{aligned}
\theta_{0} & \sim N(\hat{\theta}, 4 * \widehat{\operatorname{Cov}}(\theta)) \\
\alpha_{i 0} & \sim N\left(\hat{\alpha}, \widehat{\operatorname{Cov}}\left(\alpha_{i}\right)\right) \\
\ln \left(\sigma_{0}\right) & \sim N\left(\ln (\hat{\sigma}), I_{K}\right) \\
Q^{-1} & \sim I W\left(k_{Q}(K+1) \widehat{\operatorname{Cov}}(\theta), K+1\right) \\
V_{i}^{-1} & \sim I W\left(k_{V}(i+1) \widehat{\operatorname{Cov}}\left(\alpha_{i}\right), i+1\right) \\
W^{-1} & \sim I W\left(k_{W}(K+1) I_{K}, K+1\right)
\end{aligned}
$$

where the coefficients with hat indicate OLS-estimates from a constant VAR for a training sample with $T_{0}=40$ observations and with $k_{Q}=0.005, k_{V}=0.01, k_{W}=0.01$ so that the priors are not flat but diffuse. Note that the prior $V$ is an inverse-Wishart with degrees of freedom and scale parameter adjusted to the number of variables in the respective equation $i=2, \ldots, n$. For the constant VAR specification, we impose independent Normal-Wishart priors with identical means, variances and degrees of freedom for $\theta_{0}$ and $H_{0}$ as for the TVCVAR specification.

The model is estimated using the Gibbs sampling algorithm described in Del Negro \& Primiceri (2013). A summary is available in the online appendix of Galí \& Gambetti (2015). 


\section{Figures}

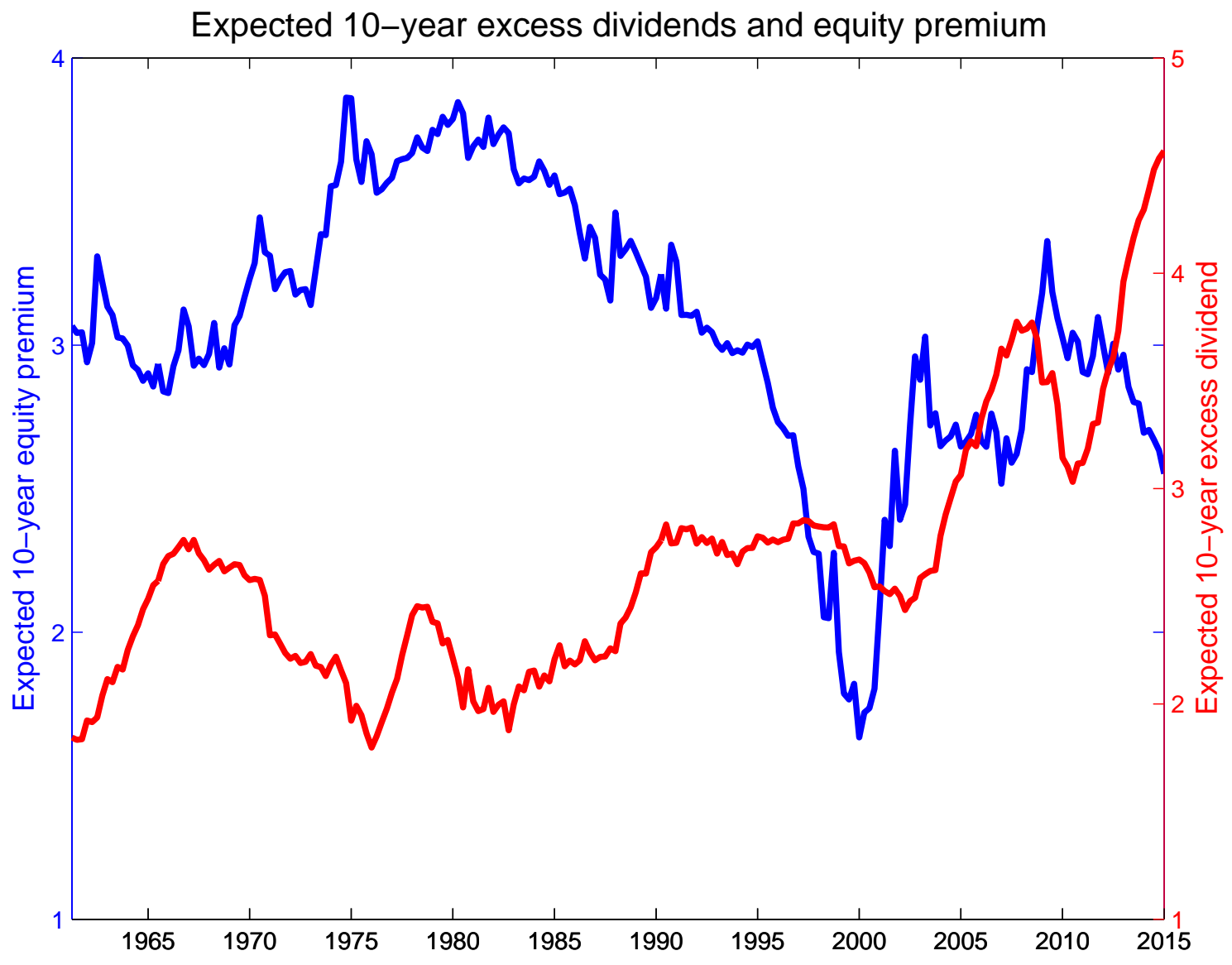

Figure 1: Estimated expected 10-year equity premium (left axis, in percent) and estimated expected excess dividends (right axis) as obtained from forecasts of the auxiliary VAR. 


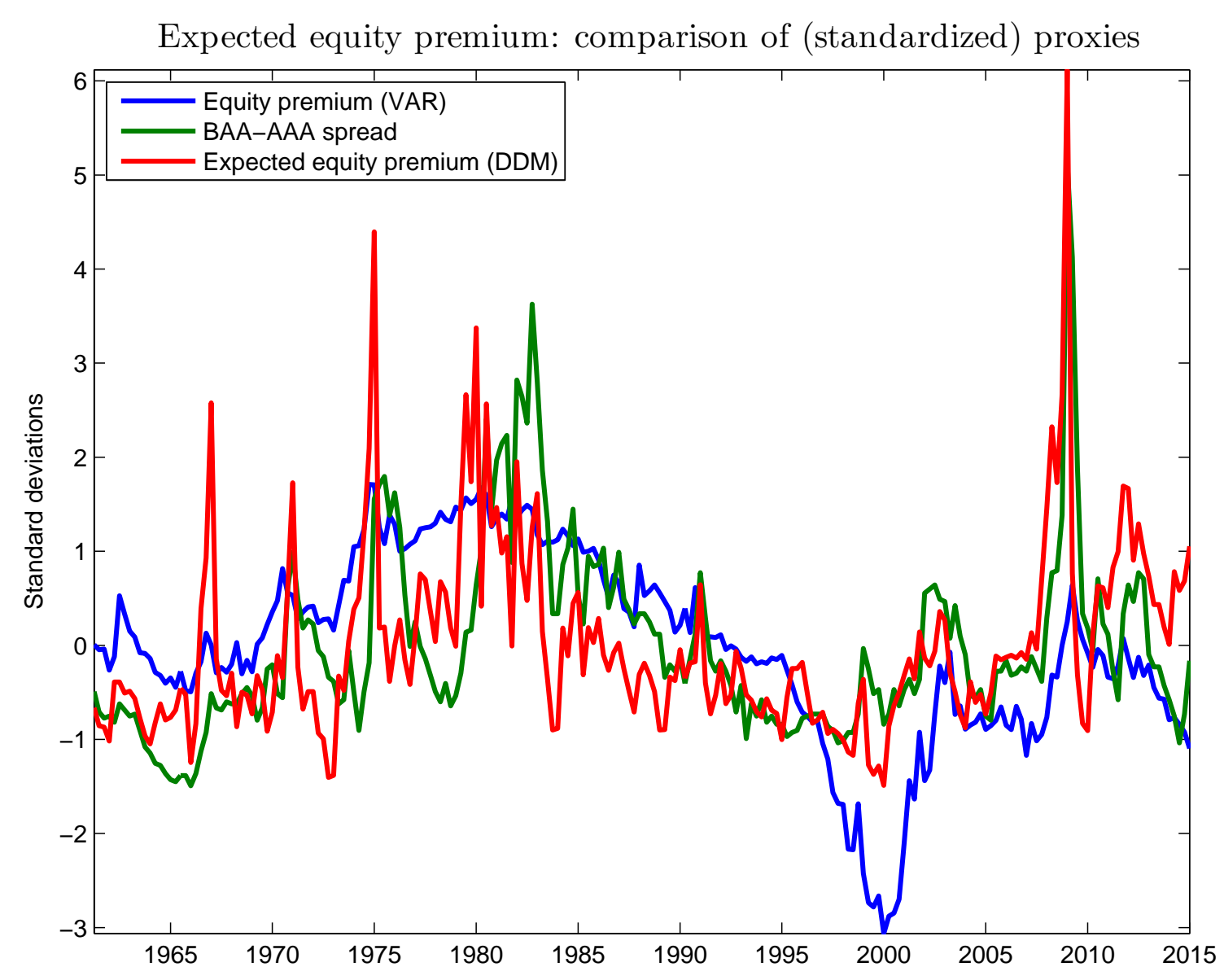

Figure 2: Comparison of standardized proxies for the expected 10-year equity premium. 


\section{Implied mispricing in the S\&P500}

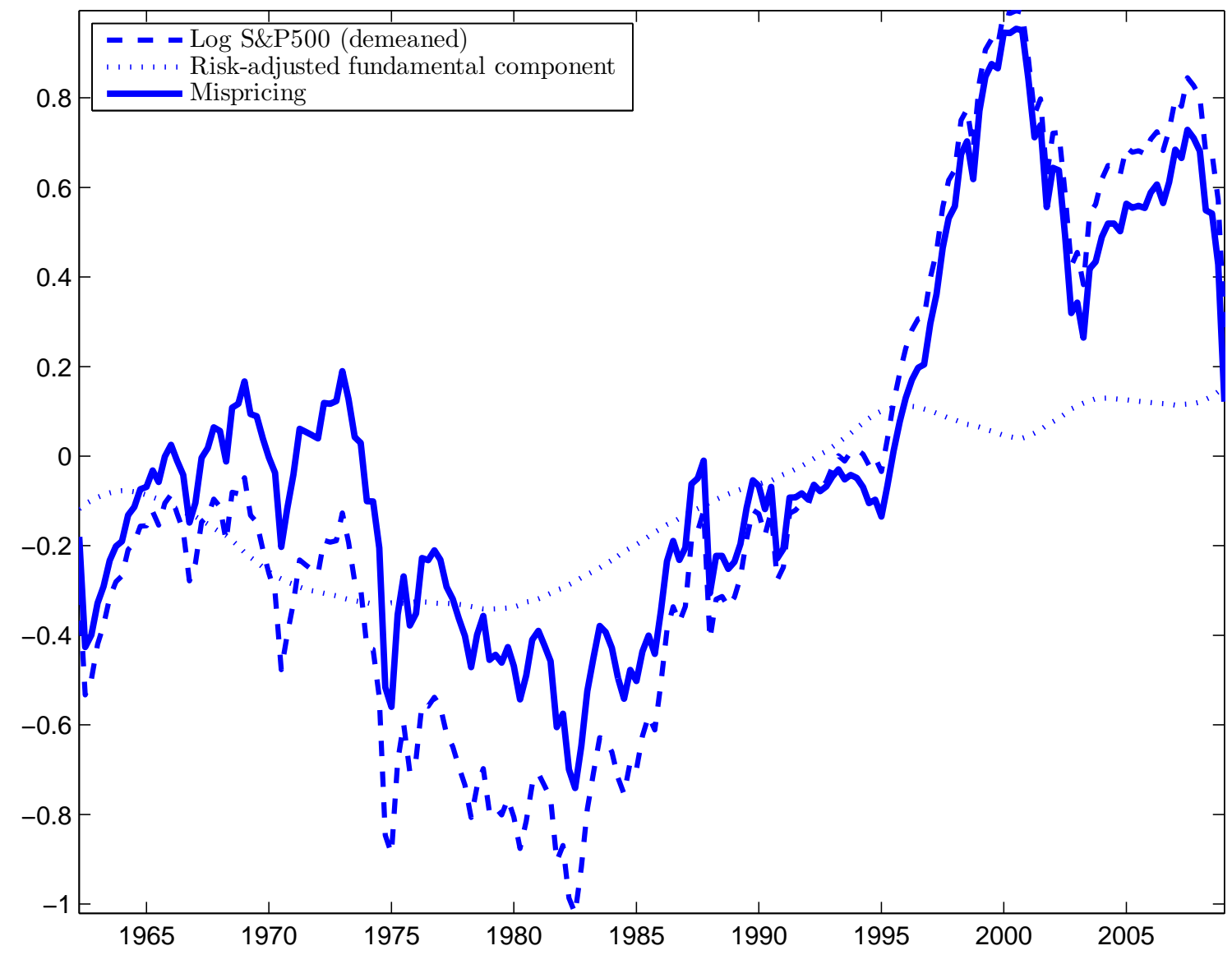

Figure 3: Log real S\&P500 index (demeaned) and implied risk-adjusted fundamental and mispricing components from equation (7). 
Panel 1: MP $\rightarrow$ Expected excess dividends
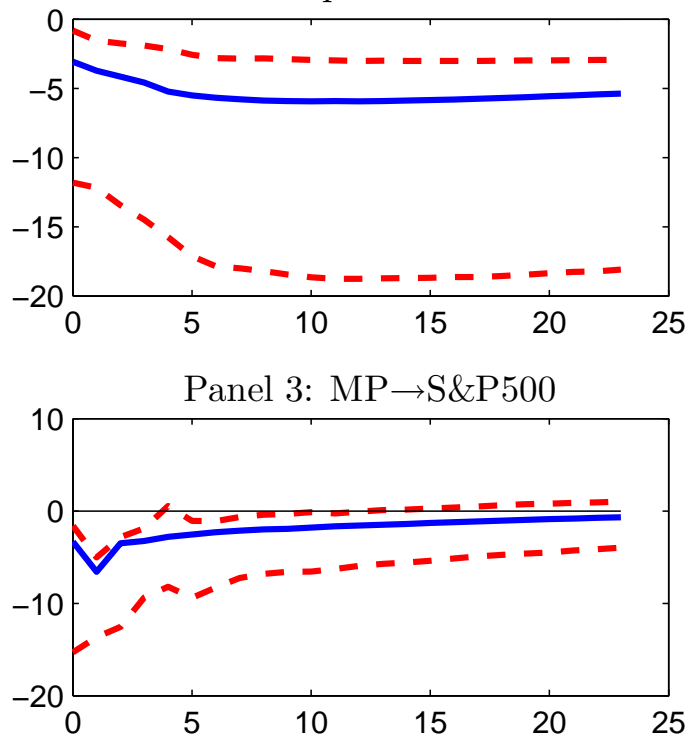

Panel 5: MP $\rightarrow$ Risk-adjusted fund. comp.

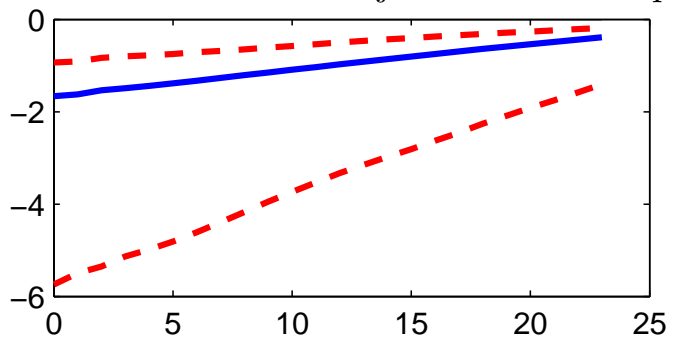

Panel 2: $\mathrm{MP} \rightarrow$ Expected equity premium

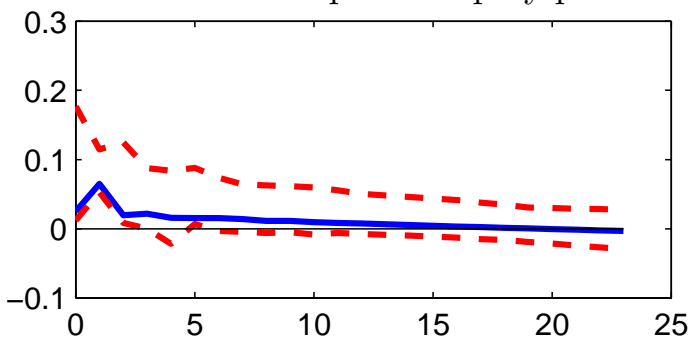

Panel 4: $\mathrm{MP} \rightarrow$ Fundamental component

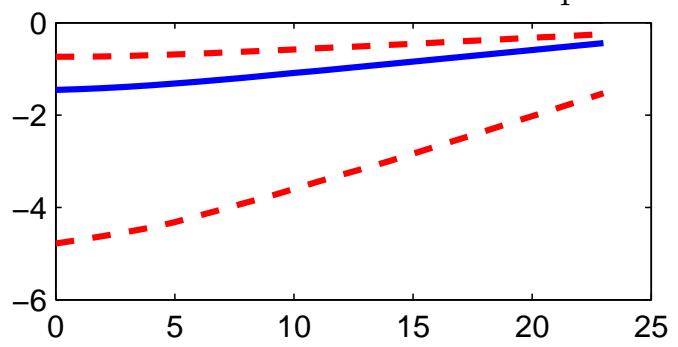

Panel 6: MP $\rightarrow$ Speculative component

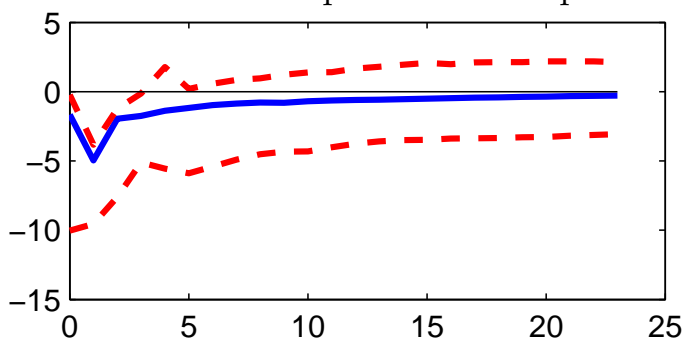

Figure 4: Cumulative responses (in percent) of expected excess dividends, the expected equity premium, the S\&P500 price and its implied components to a 100 BPS contractionary monetary policy shock. The solid blue lines indicate the impulse response functions of the median-target model obtained by minimizing the absolute deviation to the pointwise median responses to the monetary policy shock of all variables across all impulse horizons. The dashed red lines denote the $68 \%$ posterior error bands following Kilian \& Murphy (2014). 
Panel 1: MP $\rightarrow$ Expected excess dividends

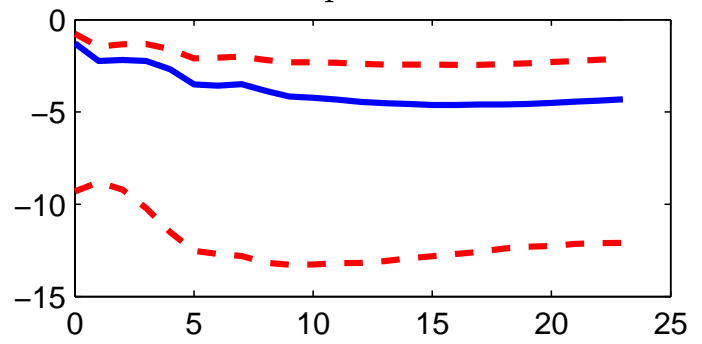

Panel 3: $\mathrm{MP} \rightarrow \mathrm{S} \& \mathrm{P} 500$

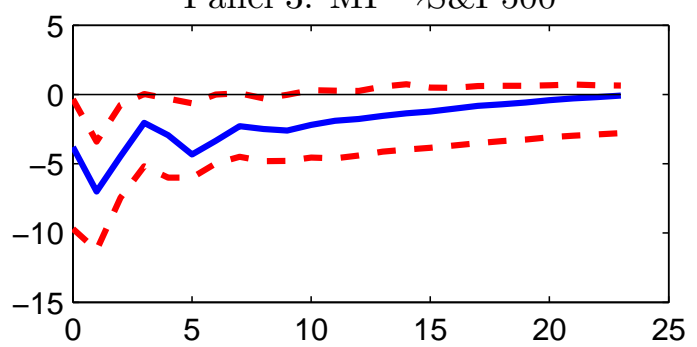

Panel 5: MP $\rightarrow$ Risk-adjusted fund. comp.

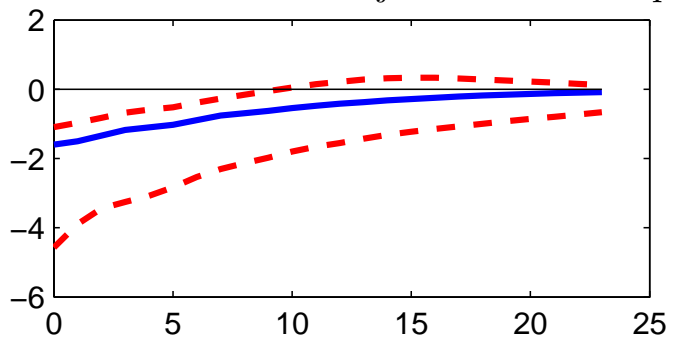

Panel 2: $\mathrm{MP} \rightarrow$ Expected equity premium

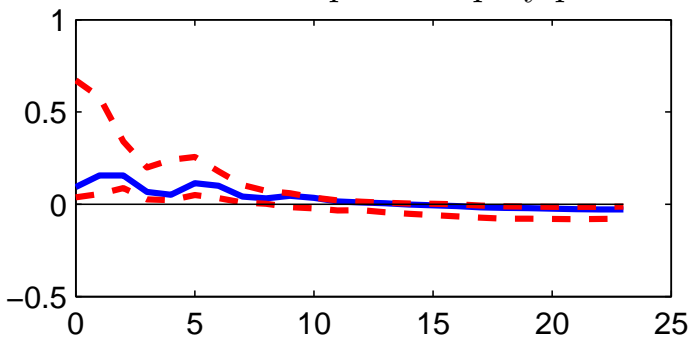

Panel 4: MP $\rightarrow$ Fundamental component

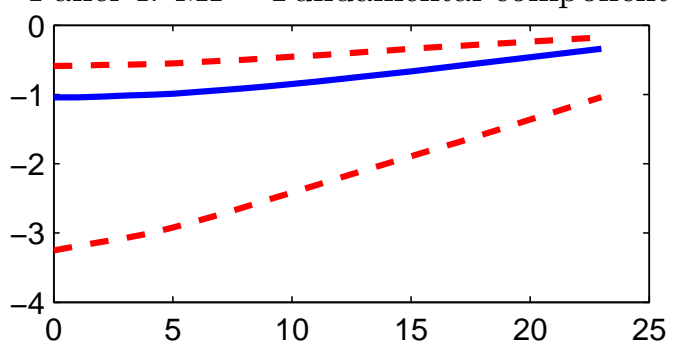

Panel 6: MP $\rightarrow$ Speculative component

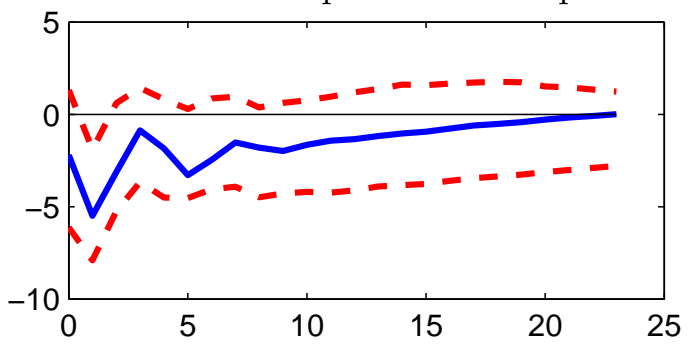

Figure 5: Cumulative responses (in percent) of expected excess dividends, the expected equity premium, the S\&P500 price and its implied components to a 100 BPS increase in the federal funds rate, where the expected equity risk premium is measured as the BAA-AAA spread. 
Panel 1: $\mathrm{MP} \rightarrow$ Expected excess dividends
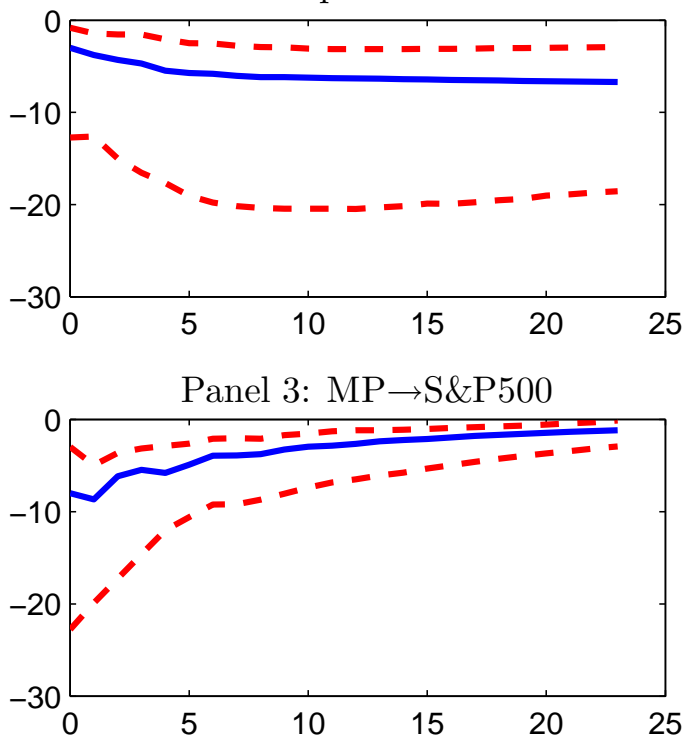

Panel 5: MP $\rightarrow$ Risk-adjusted fund. comp.

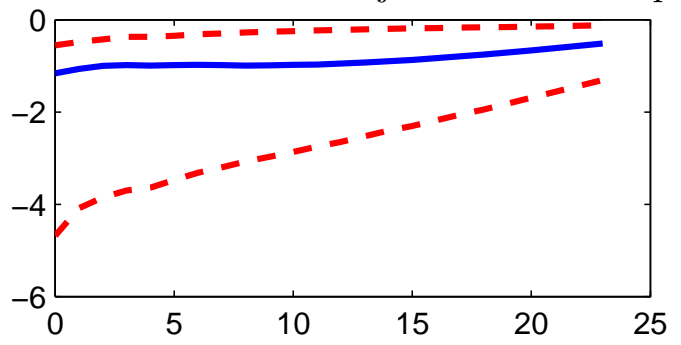

Panel 2: $\mathrm{MP} \rightarrow$ Expected equity premium

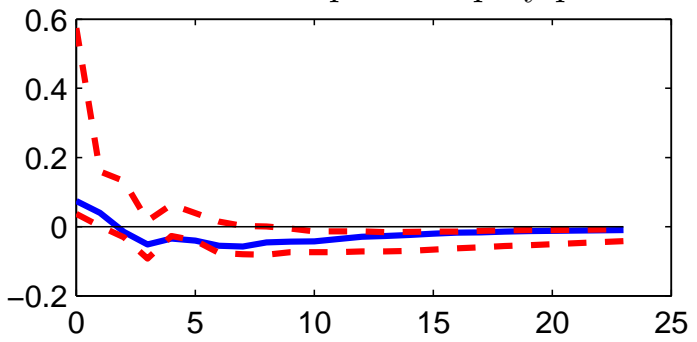

Panel 4: MP $\rightarrow$ Fundamental component

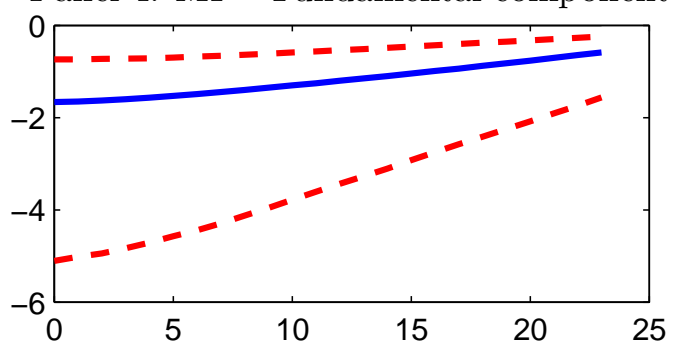

Panel 6: MP $\rightarrow$ Speculative component

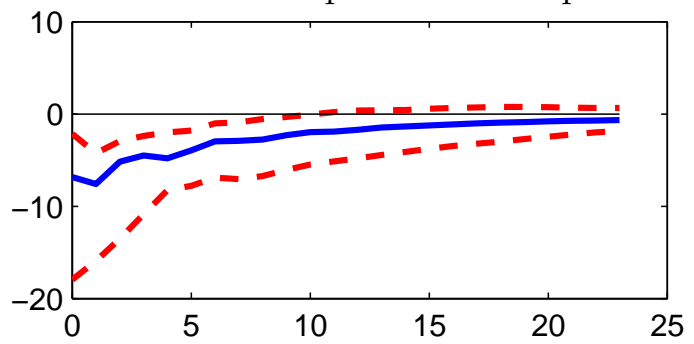

Figure 6: Cumulative responses (in percent) of expected excess dividends, the expected equity premium, the S\&P500 price and its implied components to a 100 BPS increase in the federal funds rate, where the expected equity premium is obtained from the dividend discount model (DDM). 

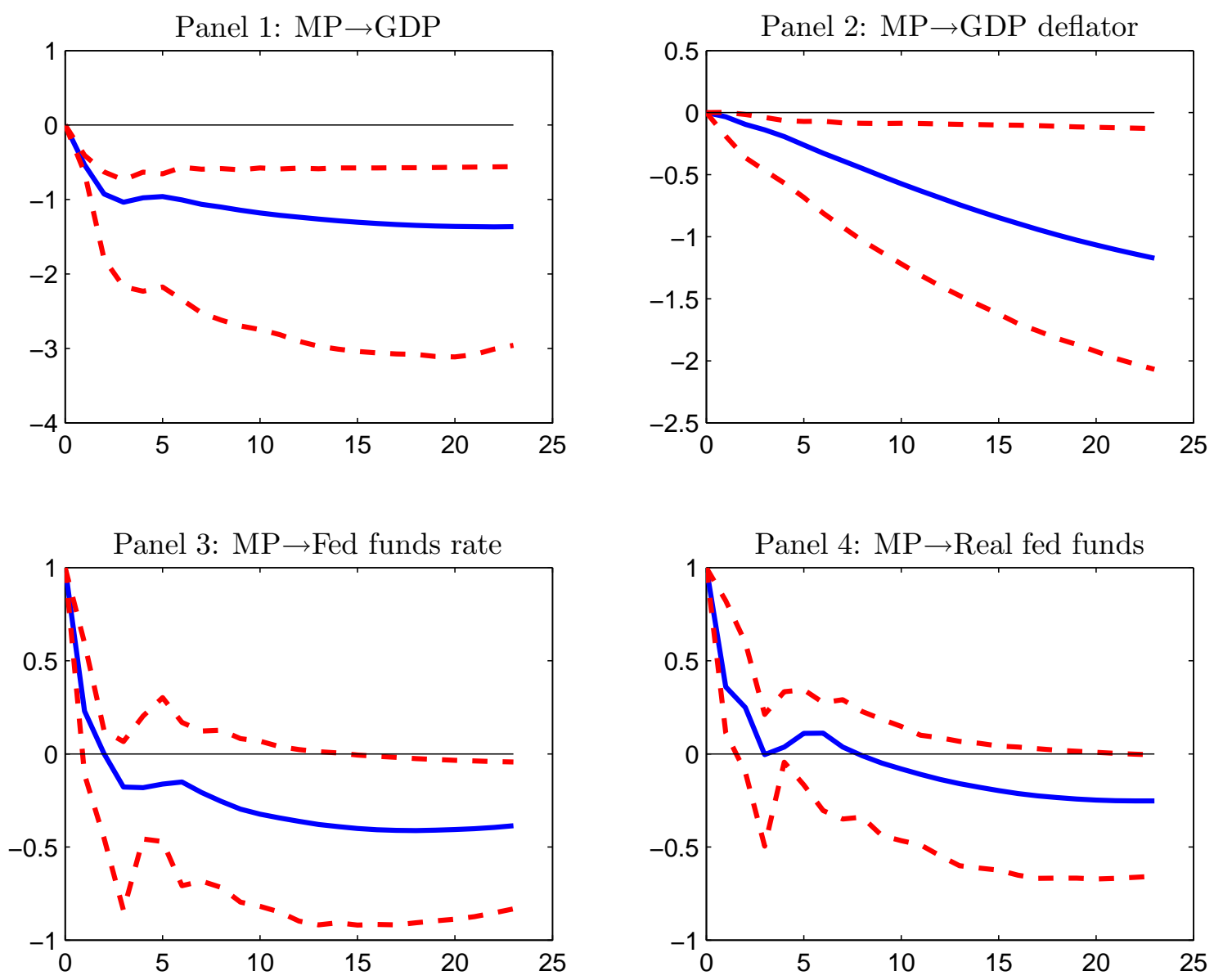

Figure 7: Cumulative responses (in percent) of real economic variables and the nominal and real policy rates to a 100 BPS increase in the federal funds rate. 

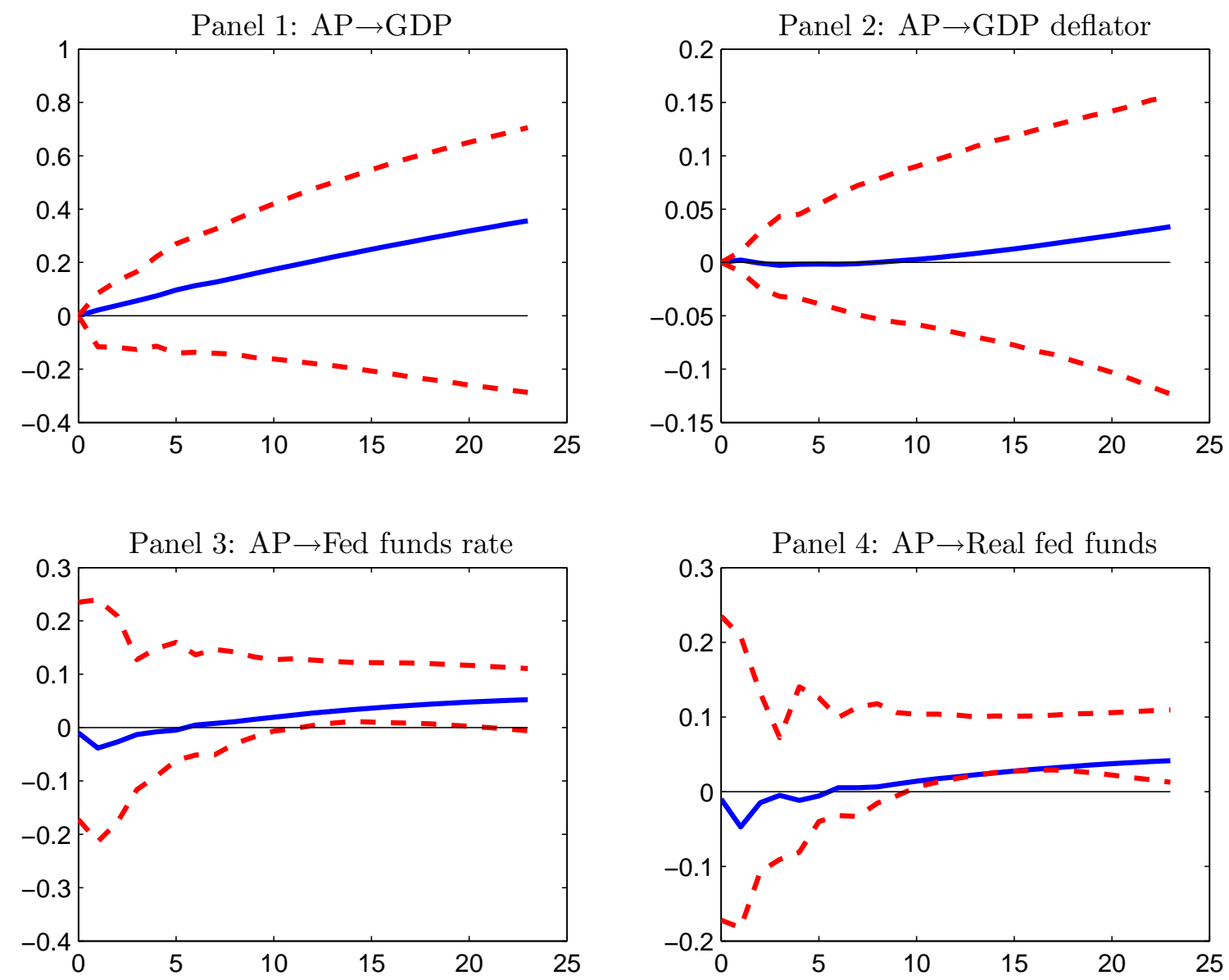

Figure 8: Cumulative responses (in percent) of real economic variables and the nominal and real policy rates to an exogenous one percent stock price increase. 


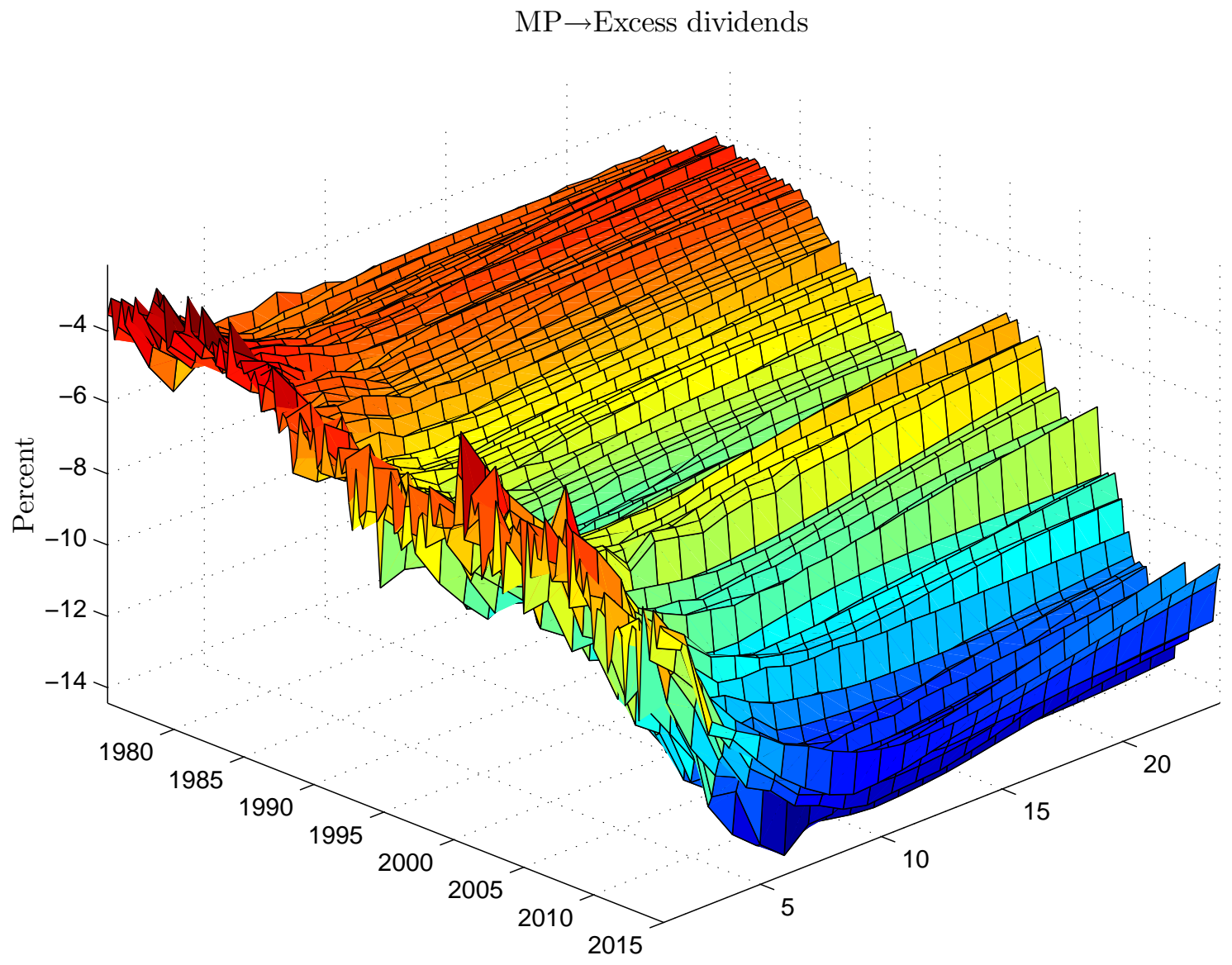

Figure 9: Cumulative, time-varying response of expected excess dividends to a 100 BPS increase in the federal funds rate. 


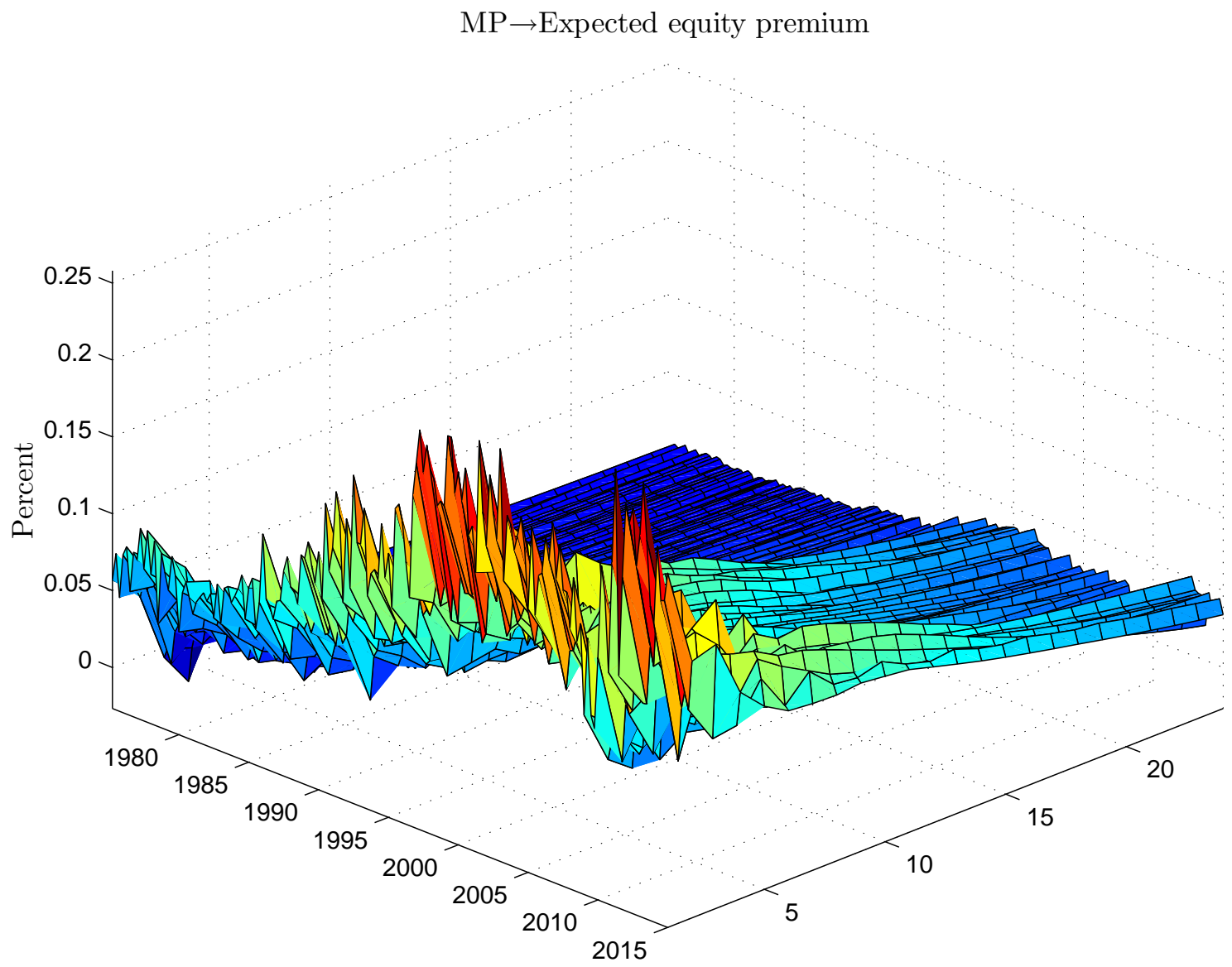

Figure 10: Cumulative, time-varying response of the expected equity premium to a 100 BPS increase in the federal funds rate. 


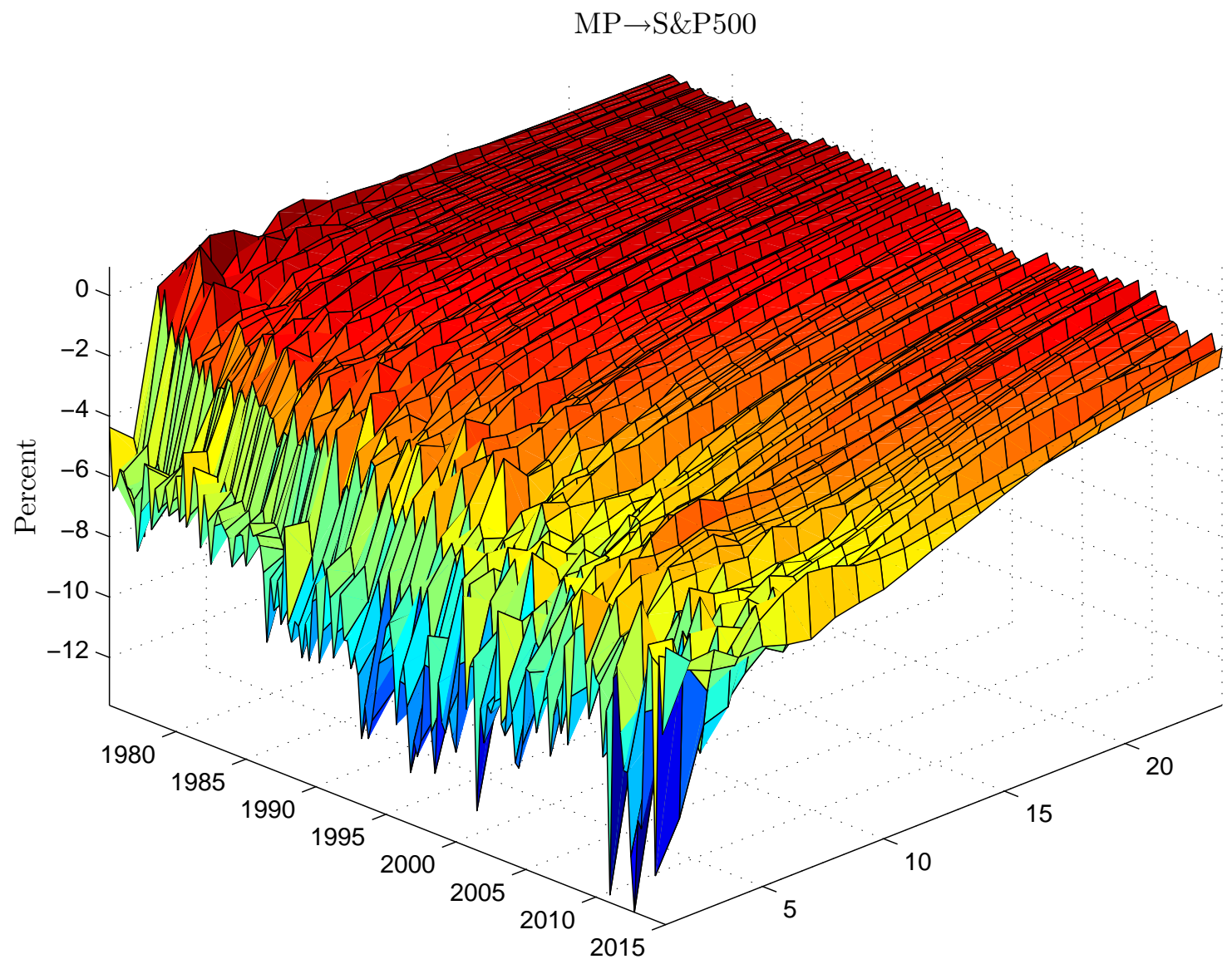

Figure 11: Cumulative, time-varying response of the S\&P500 index to a 100 BPS increase in the federal funds rate. 


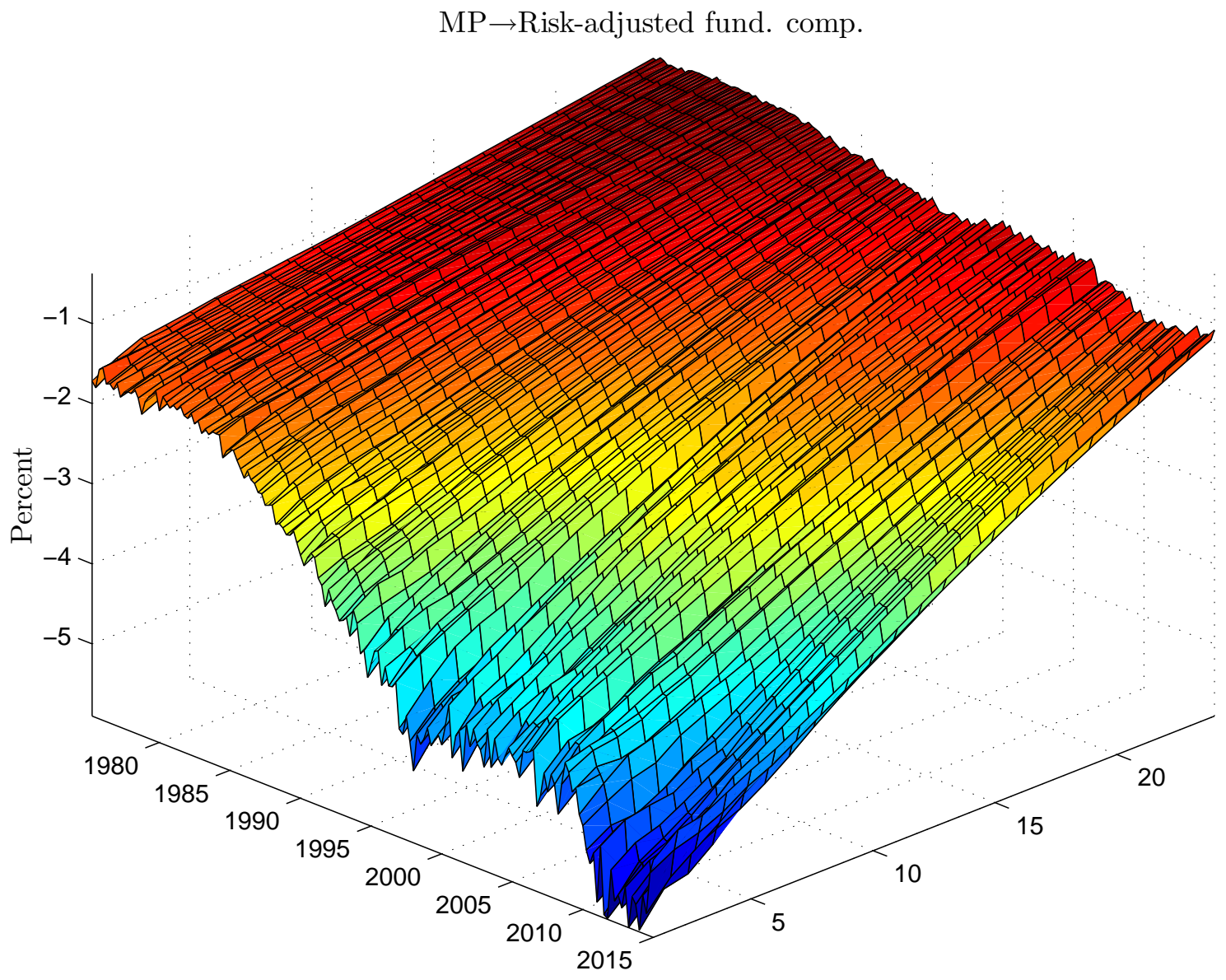

Figure 12: Cumulative, time-varying response of the risk-adjusted fundamental component to a 100 BPS increase in the federal funds rate. 


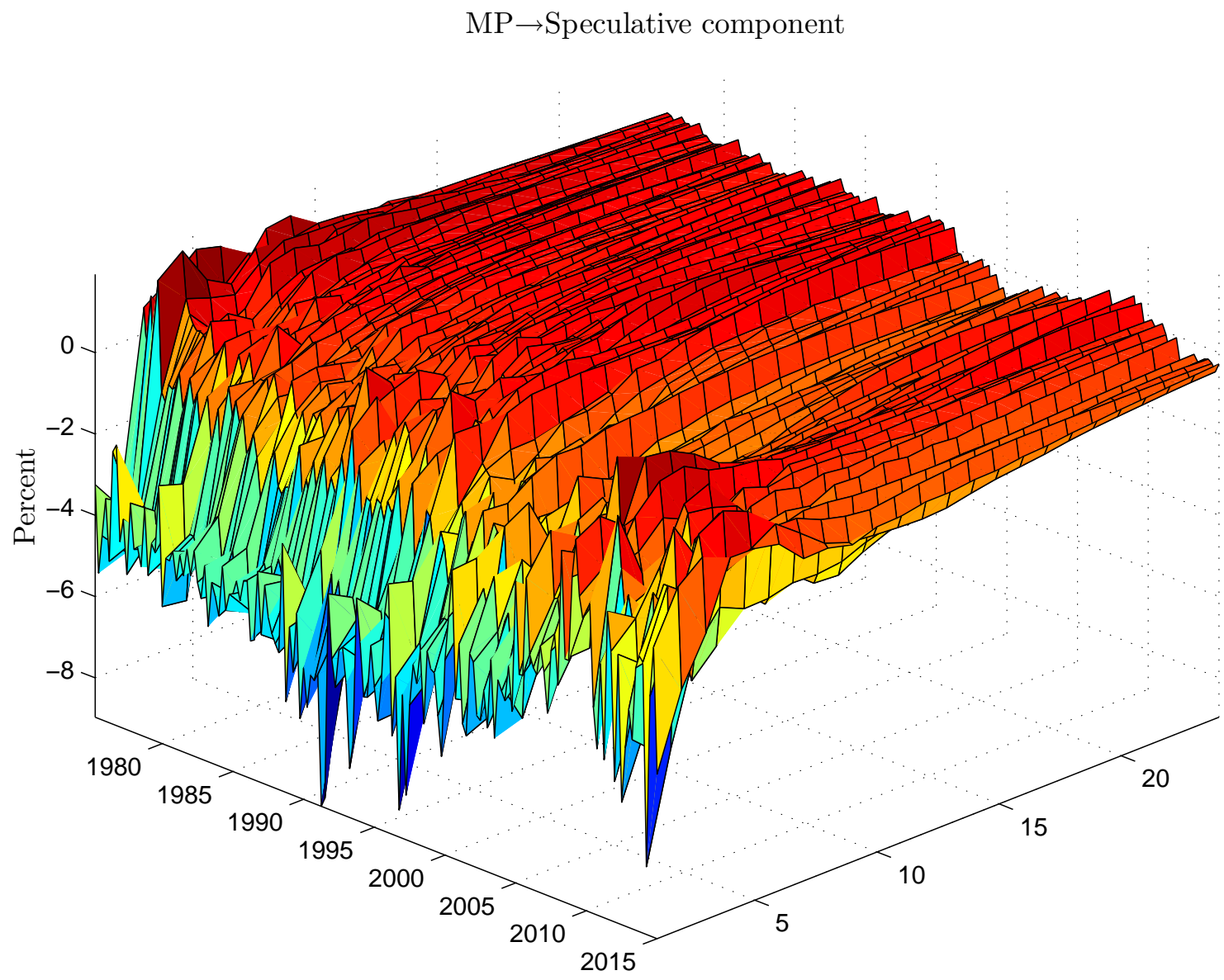

Figure 13: Cumulative, time-varying response of the mispricing component to a 100 BPS increase in the federal funds rate. 


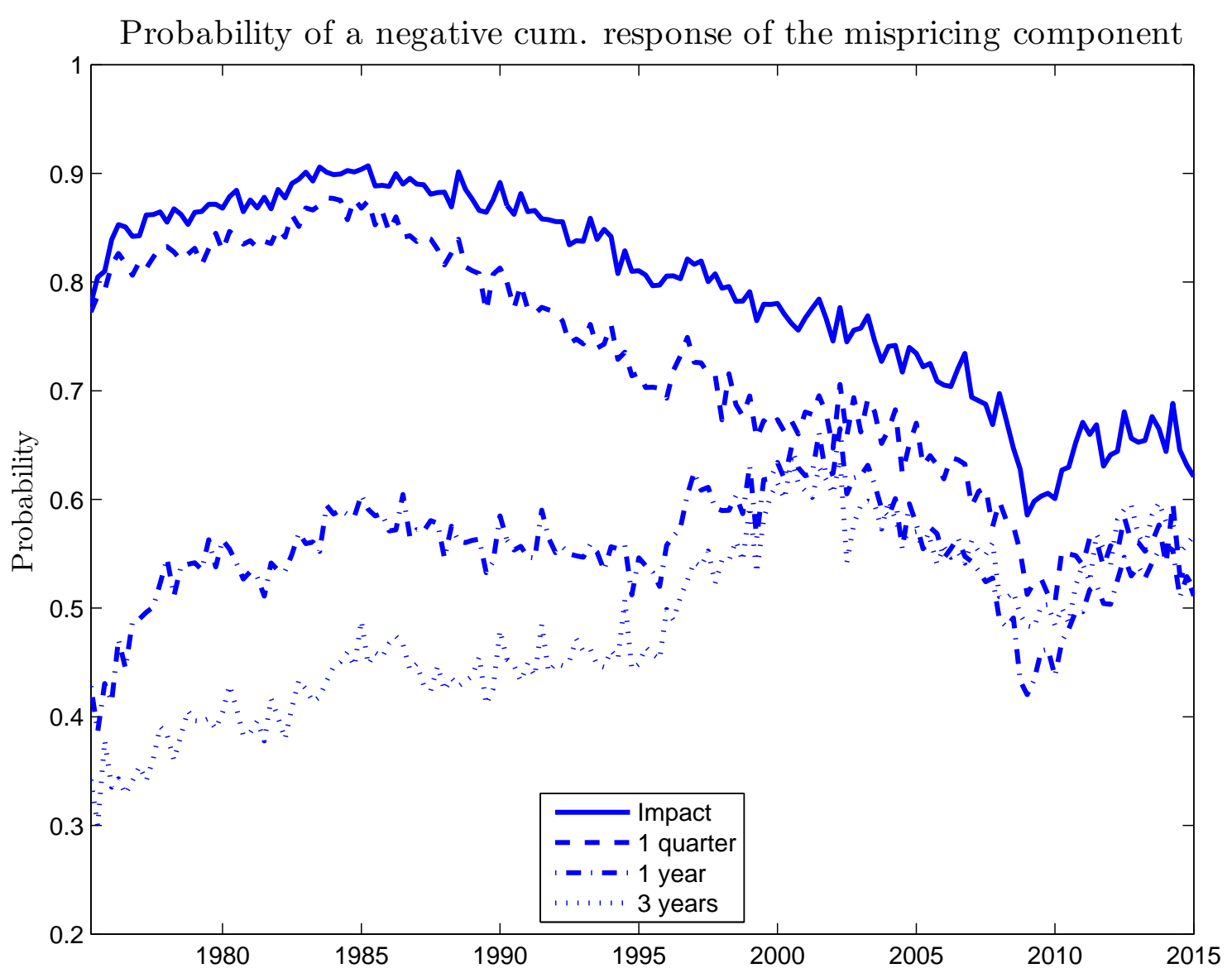

Figure 14: Probability of a negative cumulative response of the mispricing component to a 100 BPS increase in the federal funds rate over time at selected horizons. 


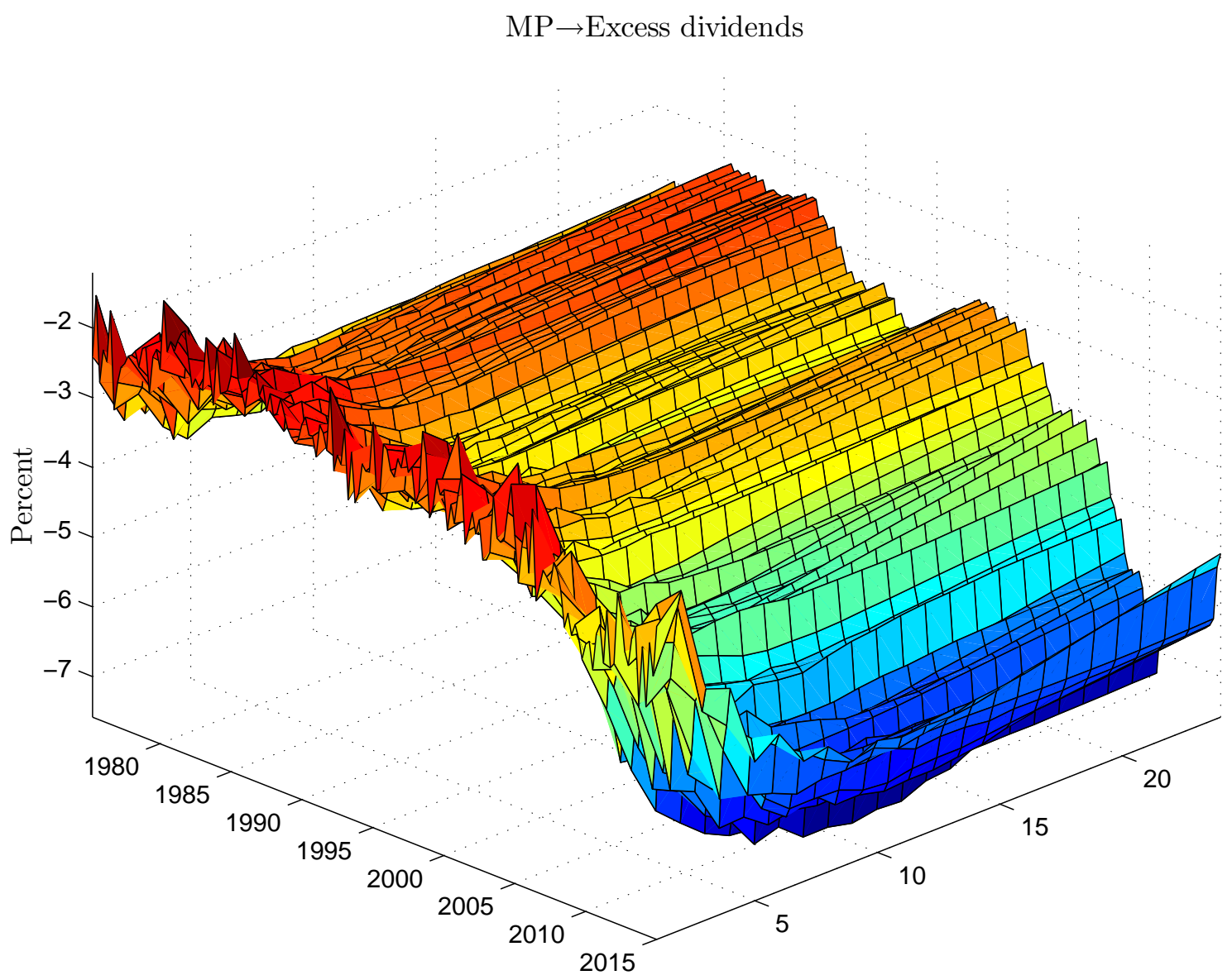

Figure 15: Cumulative, time-varying response of expected excess dividends to a 100 BPS increase in the Wu \& Xia (2014) shadow rate. 


\section{$\mathrm{MP} \rightarrow$ Expected equity premium}

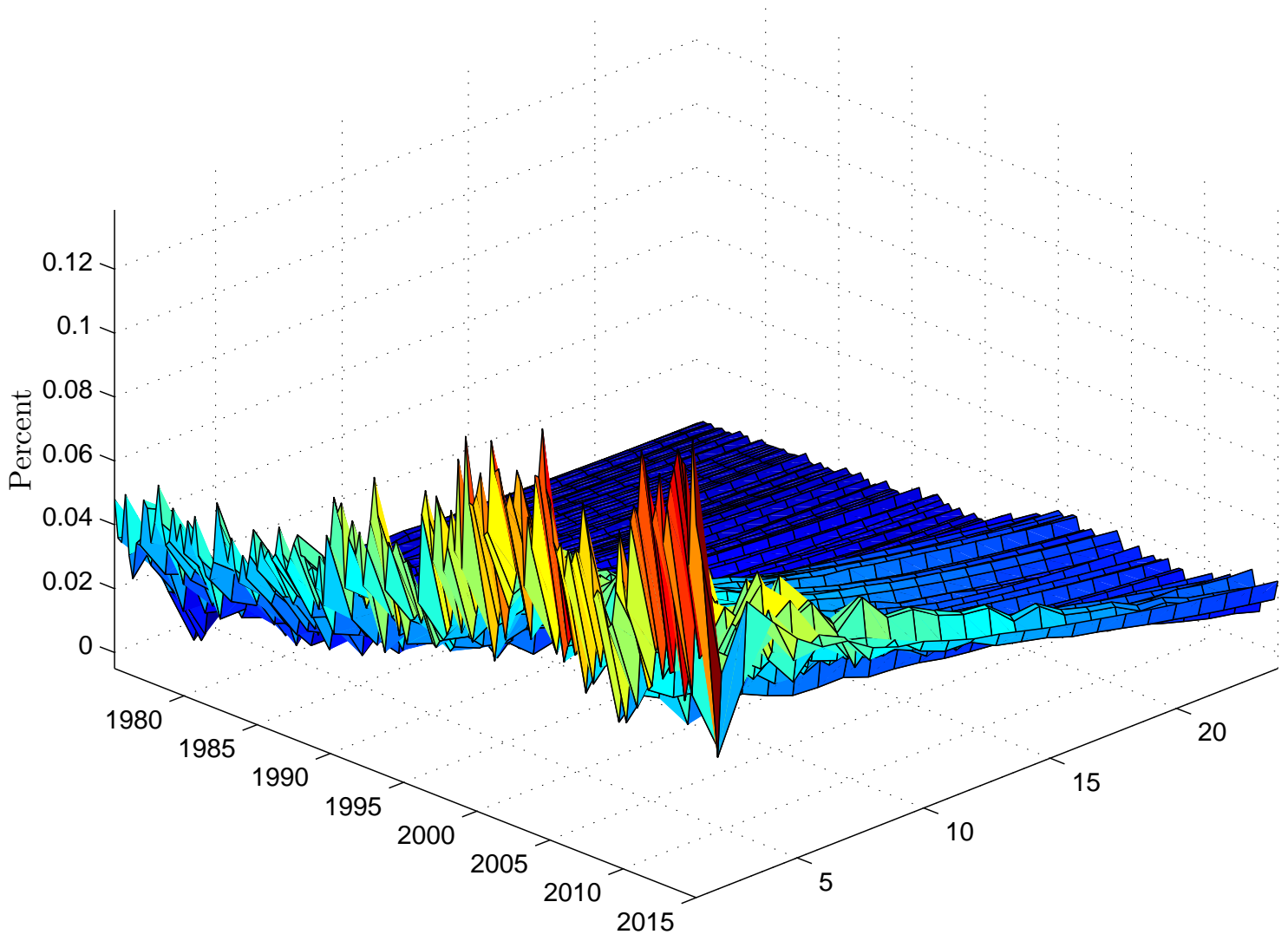

Figure 16: Cumulative, time-varying response of the expected equity premium to a 100 BPS increase in the Wu \& Xia (2014) shadow rate. 


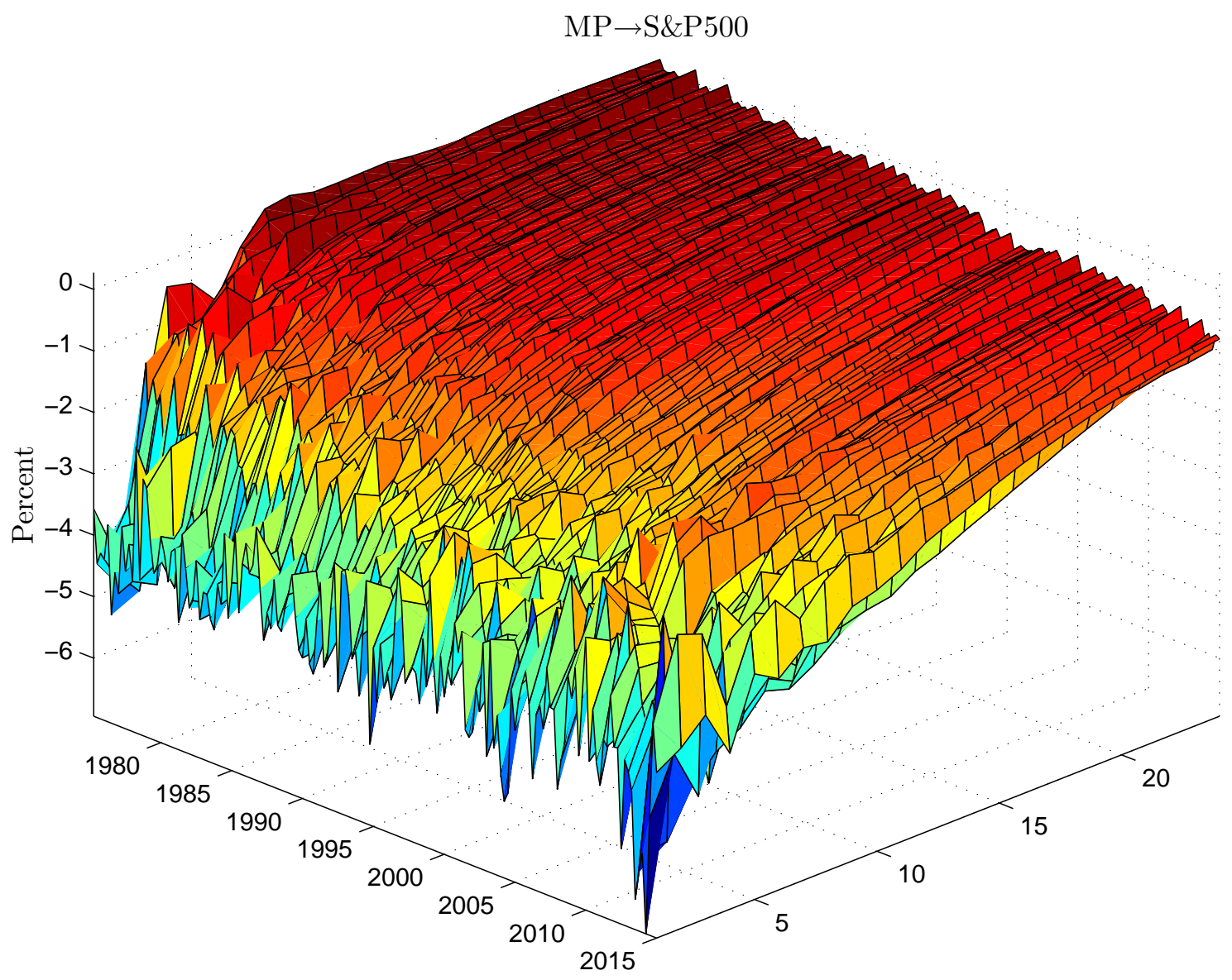

Figure 17: Cumulative, time-varying response of the S\&P500 index to a 100 BPS increase in the Wu \& Xia (2014) shadow rate. 


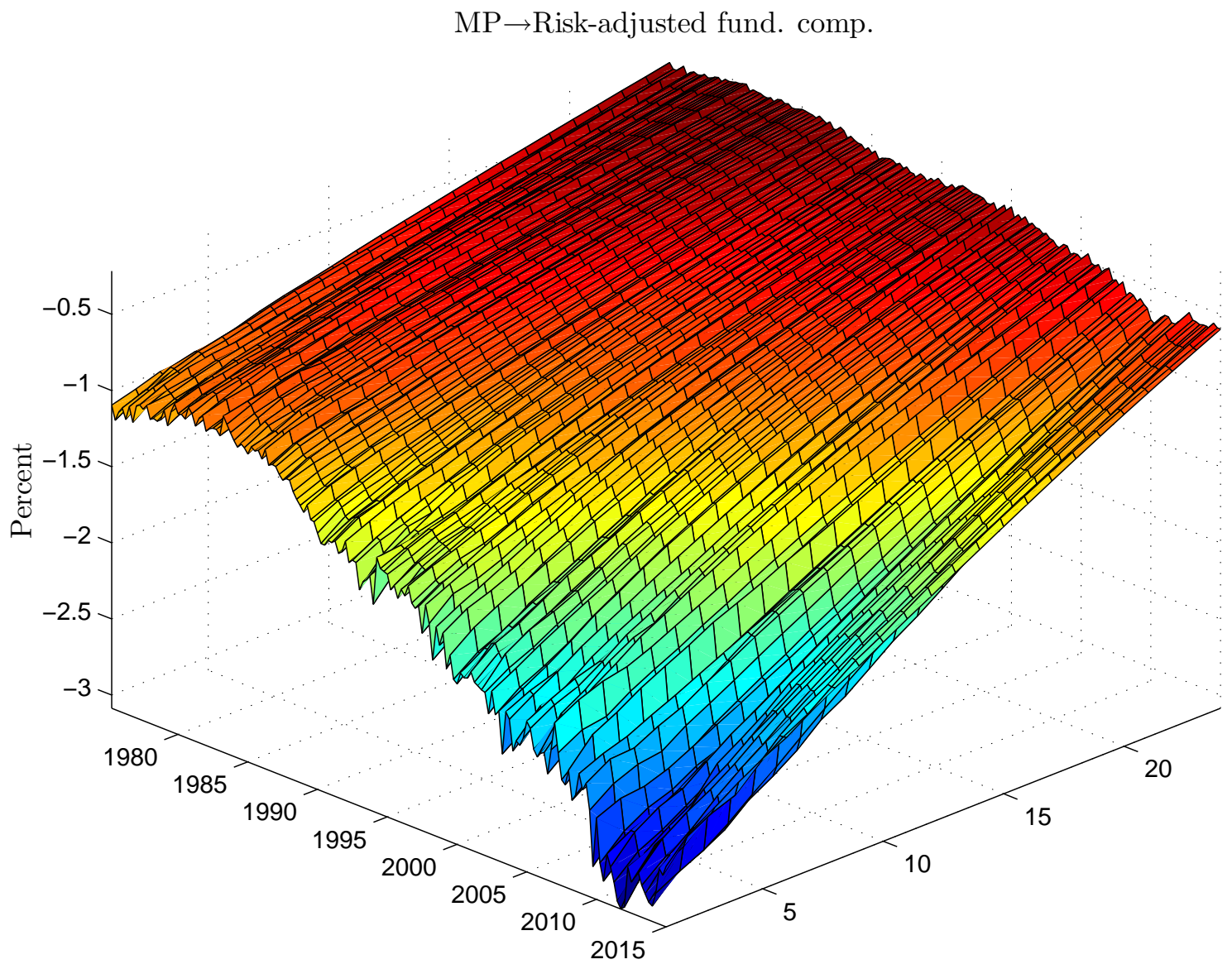

Figure 18: Cumulative, time-varying response of the risk-adjusted fundamental component to a 100 BPS increase in the $\mathrm{Wu} \& \mathrm{Xia}(2014)$ shadow rate. 


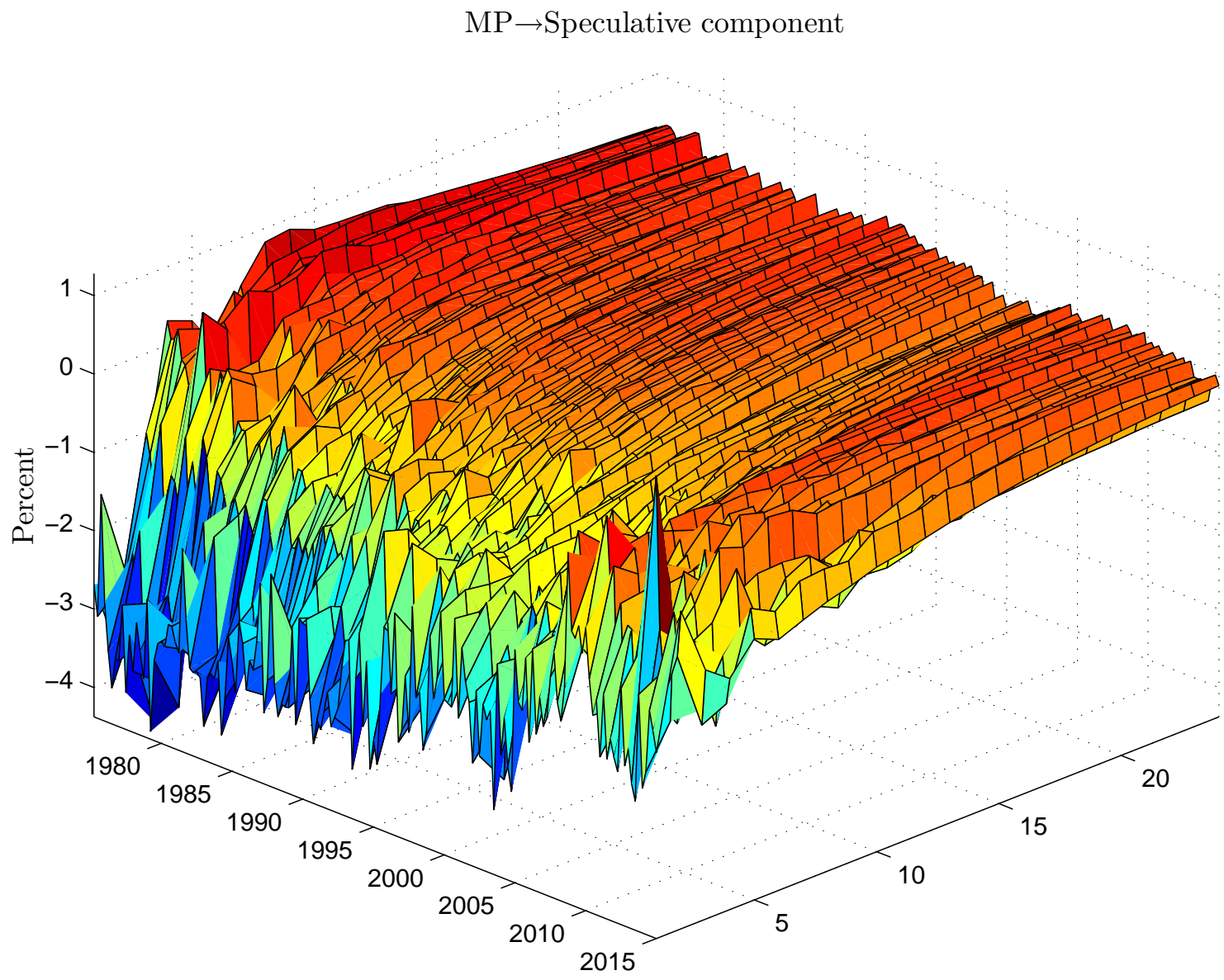

Figure 19: Cumulative, time-varying response of the mispricing component to a 100 BPS increase in the Wu \& Xia (2014) shadow rate. 